\title{
La época romana en Darró (Vilanova i la Geltrú, Barcelona) *
}

\author{
Alberto López Mullor \\ JAVIER FIERRO Macía
}

\section{INTRODUCCION}

Las noticias de la existencia de la villa romana de Darró son muy antiguas y fragmentarias. Para encontrar las primeras referencias al yacimiento es necesario remontarse a la "Carta del Doctor D. Jayme Pascual... al Doctor D. Francisco Papiol de Padró", fechada en 1789 y transcrita casi por entero en la Historia de Villanueva y Geltrú, publicada por Coroleu hace más de un siglo ${ }^{2}$. El erudito canónigo menciona en su exposición «las fábricas subterráneas que se han descubierto (cerca de la ermita de Sant Gervasi) y los muchos sepulcros llenos de huesos y calaveras pasado el cráneo de algunas de ellas con un clavo". Este párrafo, glosado acertadamente por los autores de la Carta arqueológica de la provincia de Barcelona ${ }^{2}$, nos ilustra sobre la posible existencia de un poblado ibérico, a tenor del rito practicado con los cráneos, y da a entender que la presencia de las ruinas era cosa sabida hace doscientos años. Por lo que se refiere a la villa romana, en la Carta arqueológica se

* Este articulo es continuacion del publicado en el tomo 1. serie Historia Antigua, de esta revista, en homenaje al profesor Eduardo Ripoll Perello (cf. bibliografia: LoPEz MULLor. FierRo, $1988 \mathrm{c}$ ). Con ambos trabajos pretendemos dar a conocer una panoramica general de las excavaciones en el yacimiento durante los últimos años.

COROLEU, 1979: 29-34.

Almagro, Serra, Colominas. 1945: 230 
recoge la noticia del hallazgo de un mosaico en blanco y negro, que se destruyó, y de un "hombre de piedra" cuyo paradero se ignora ${ }^{3}$.

A pesar de todo, las primeras evidencias tangibles de la época romana que han llegado a nosotros se localizaron a raiz de las obras del ferrocarril, en 1880: se trata de un capitel y una basa de columna que hoy se conservan en el museo del castillo de La Geltrú, junto con otros similares descubiertos posteriormente (infra). Poco despues se dio a conocer de forma cientifica el único epigrafe descubierto en el yacimiento hasta la fecha - del que nos ocuparemos más adelante-, pero ya habia sido publicado por Pascual y Coroleu ${ }^{4}$. Tan vistosos hallazgos impulsaron al inquieto y malogrado Albert Ferrer Soler a averiguar el verdadero alcance de las ruinas, y junto con algunos colaboradores realizo los primeros estudios que podriamos llamar arqueológicos, en el sentido actual del término ${ }^{5}$.

Una vez desaparecido el señor Ferrer Soler, el interés por la villa -en aquellos tiempos el establecimiento ibérico apenas se conociacontinuó, y el profesor Antonio Arribas llevó a término dos campañas de excavación sistemática. Los trabajos de entonces se concentraron en un lugar situado entre el lecho del torrente de Sant Gervasi, la playa y la vía férrea (en una finca que actualmente llamamos "zona 1») (lám. 1), y sirvieron para delimitar el muro que cerraba la pars urbana a mediodia y diversos ámbitos de la residencia (I, VIII, IX, XIV, XV, XVI), algunos de los cuales se vaciaron totalmente. Esta investigación se publicó al poco ${ }^{6}$, y durante mucho tiempo ha sido la unica noticia conocida sobre el sector romano del yacimiento. Incluso, algunas de las conclusiones, como la hipotética destrucción acaecida durante la razzia franca de los años sesenta del siglo III, se han convertido en referencia clásicas de los tratados de historia antigua ${ }^{7}$, aunque, como veremos, era necesario revisarlas y matizarlas. En cualquier caso, la excavación de Arribas fue modélica para su tiempo, tanto por lo que se refiere al trabajo de campo como por la manera de presentar los resultados, y nuestra actuación reciente se ha beneficiado de ello.

Las últimas excavaciones han tenido un carácter diferente de las que se hicieron en la década de los cincuenta. Desde 1980, el Museo Ar-

Ibidem

Ibidem. 29-30; ClL, 4.444; un estudio reciente en: Castellano, 1986.

Ferrer Soler, 1944; Idem, 1947-1948; Idem, 1955

Arrieas, 1956: ldem, 1959.

P. e.: Tovar, BlazQuez, 1975: 137 


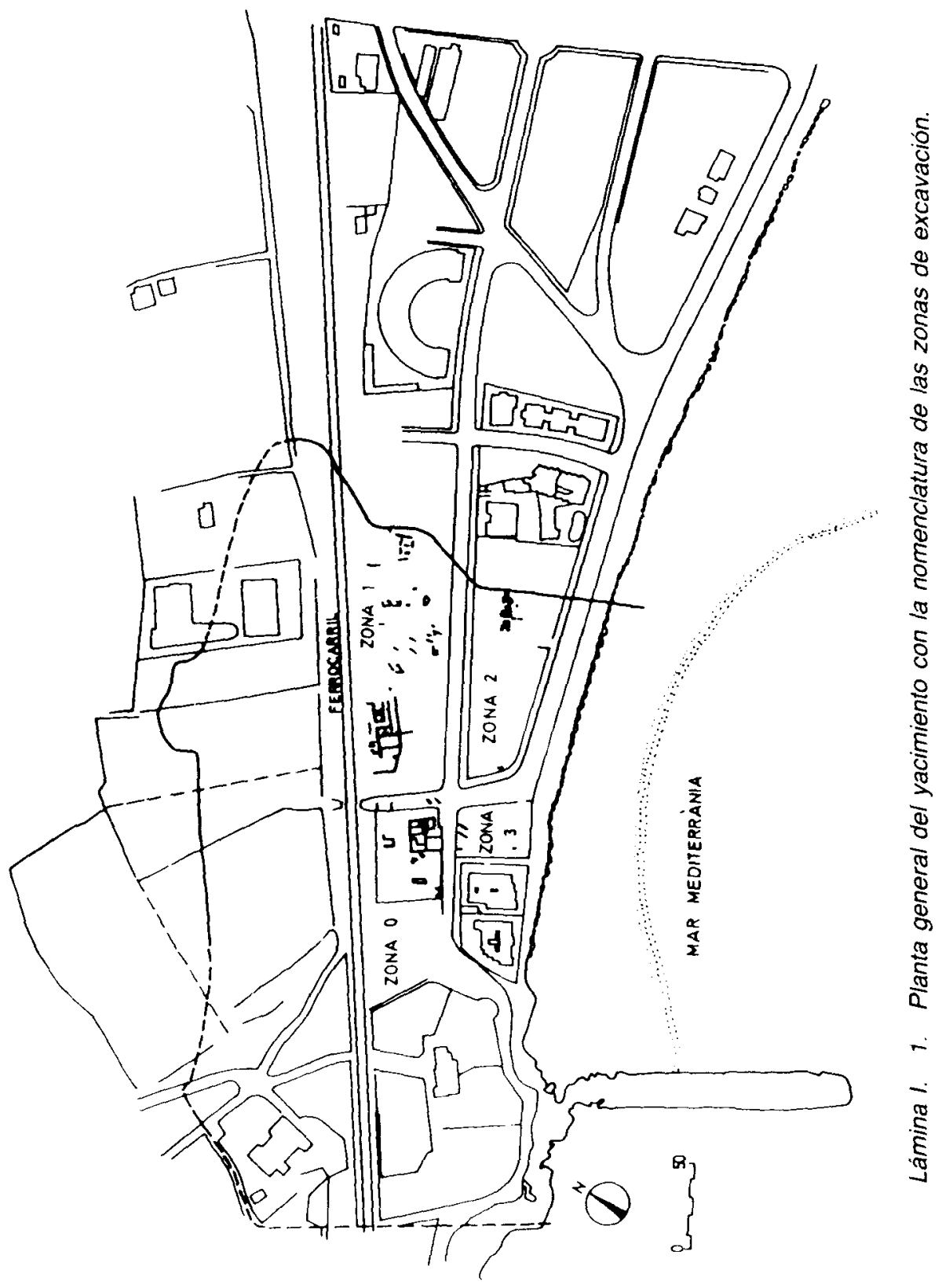




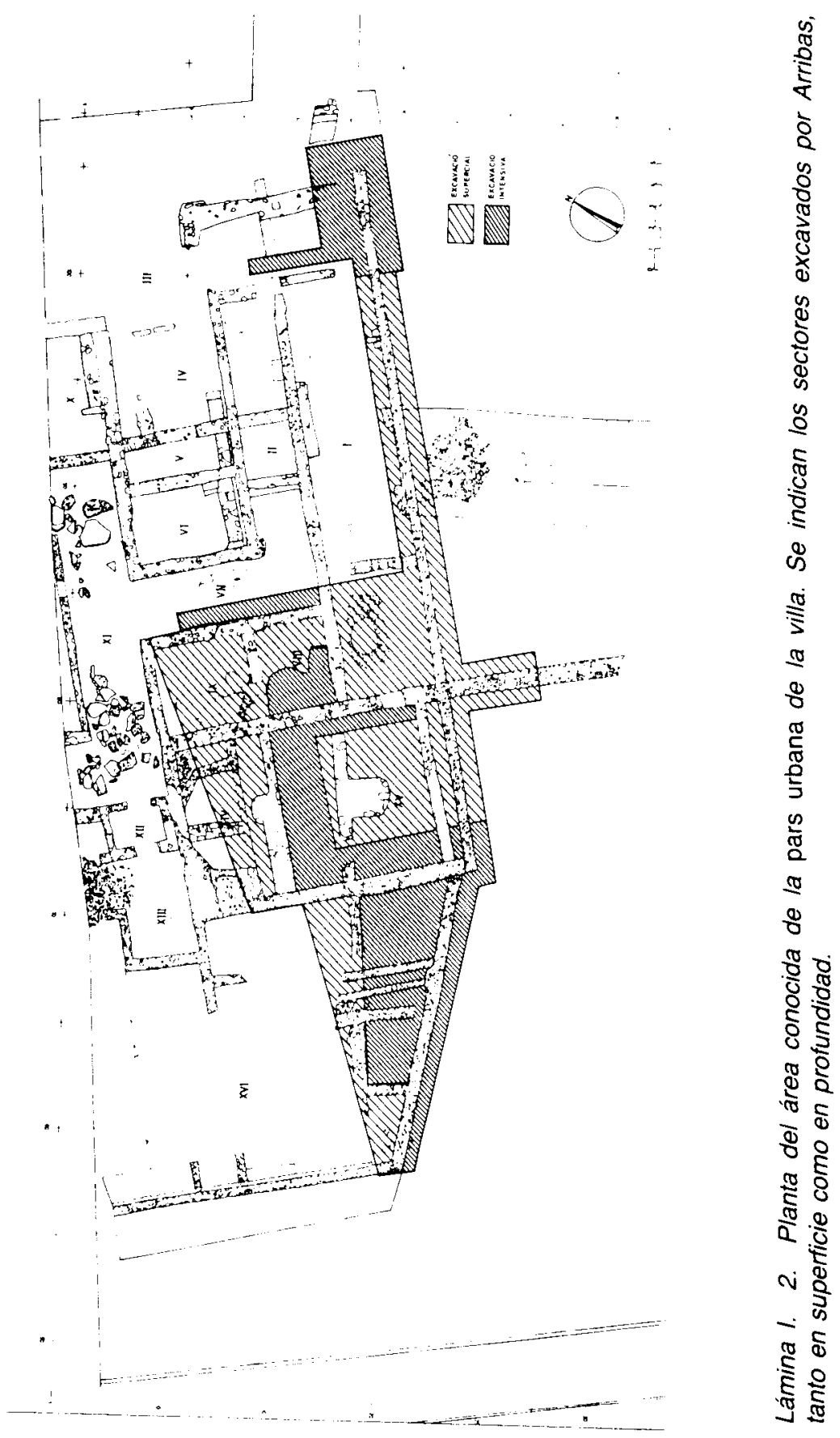


queológico de Barcelona había desarrollado campañas de excavación sucesivas y, a raíz de sus alentadores resultados, el año 1983, el Ayuntamiento de Vilanova i la Geltrú solicitó a la Diputación de Barcelona el estudio sistemático, la ordenación y la restauración de las ruinas de Darró, para poder abrirlas al público. Desde entonces, el servicio de $\mathrm{Pa}$ trimonio Arquitectónico de la Corporación inició esta tarea en estrecha colaboración con los servicios técnicos municipales.

En primer lugar era necesario conocer la extensión real del yacimiento, lo que implicó un trabajo de prospección muy largo y oscuro, que se desarrolló básicamente en los años 1984 y 1985, aunque anteriomente ya se habian realizado algunos sondeos con la misma finalidad ${ }^{8}$. Una vez alcanzado este objetivo, se empezó a excavar en extensión toda el área arqueológica, a fin de obtener una visión cualitativa de los restos que contenia. Esta actuación, en principio poco espectacular, que se llevó a término en 1985 y 1986, proporcionó la localización del alfar romano de la "zona 2" (lám. VIII) ${ }^{9}$, que se excavó seguidamente. Era la primera vez que investigábamos de verdad restos de la villa, pues hasta entonces las únicas estructuras imperiales exhumadas en Darró durante las excavaciones recientes habían sido los restos de alguna estancia muy arrasada situada en la "zona 0", que se puso al descubierto a lo largo de los trabajos de salvamento coordinados por el señor Ferrer Marti ${ }^{10}$.

Casi paralelamente al descubrimiento de la figlina, empezamos a delimitar un grupo de ámbitos de la pars rustica (lám. VII), que habian estado dedicados a la transformación de las materias primas agrícolas. También estaban muy arrasados, pero resultaban suficientemente interesantes para documentar su funcionamiento. Además, dentro de la misma campaña, destapamos las ruinas descubiertas por el profesor Arribas (láms. II.2, IV.2) y excavamos en extensión toda la pars urbana que había al sur del ferrocarril, donde también se practicaron algunos sondeos.

A lo largo de 1987 y 1988 continuó la investigación cualitativa del yacimiento, y los esfuerzos afectaron algunas dependencias rústicas de época romana, pero básicamente se centraron en las importantes estructuras ibéricas aparecidas al lado o debajo de las mismas. También se realizaron estudios sobre la configuración del medio físico antiguo, ya

Un resumen de los resultados de las prospecciones en: LOPEz Mullor, 1986.

Primera noticia de la producción de ánforas: LOPEz Mullor, FerRer MARiti, 1982 d; más precisiones: LOPEZ Mullor, 1989 b; descripción de la figlina: LoPEz Mullor. Fierro, 1987; Idem, 1988 b.

10 Ferrer Marti, 1978; más información: Lopez Mullor, Feraer Marti, 1982 a: Idem, 1984. 


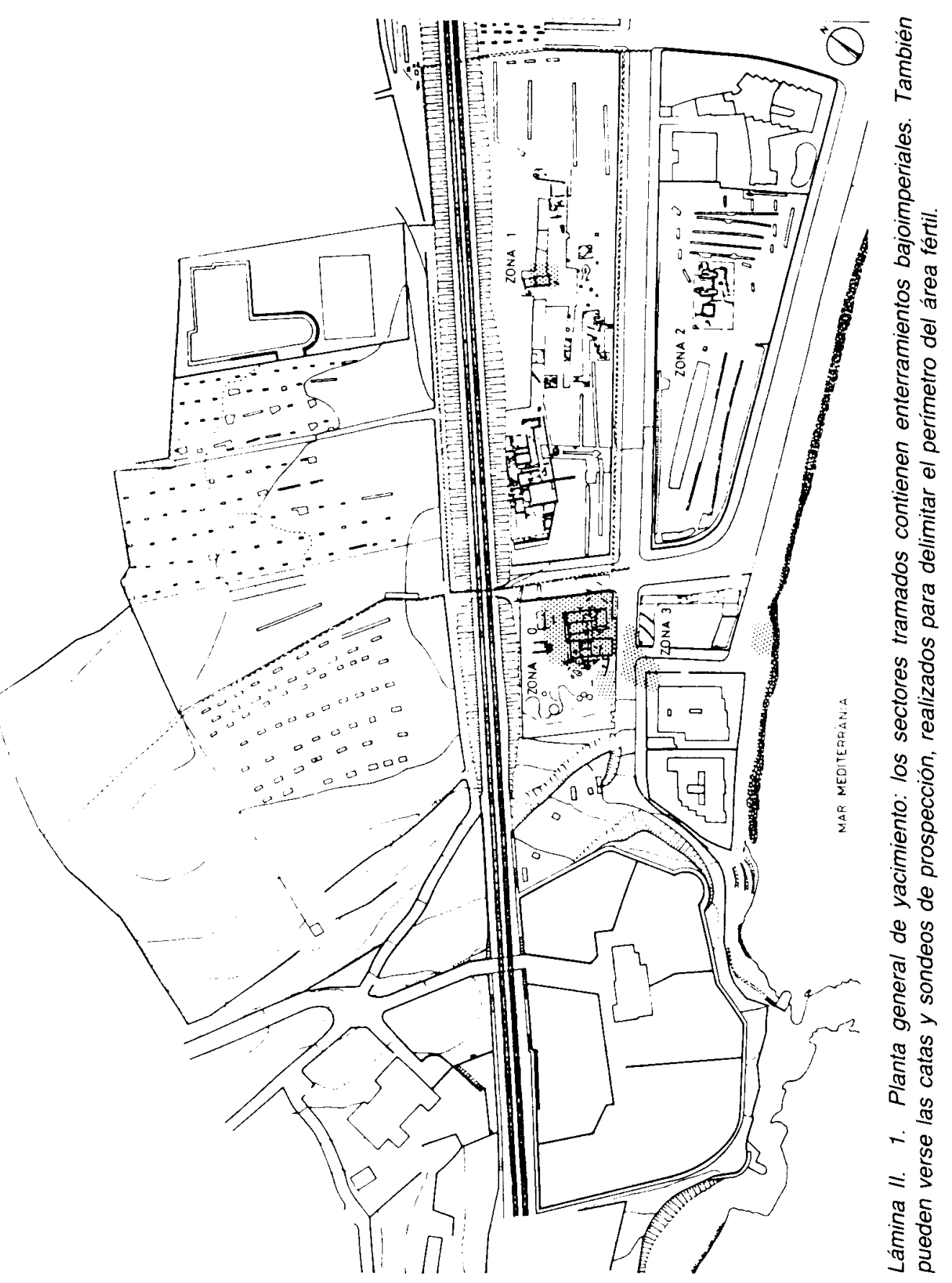




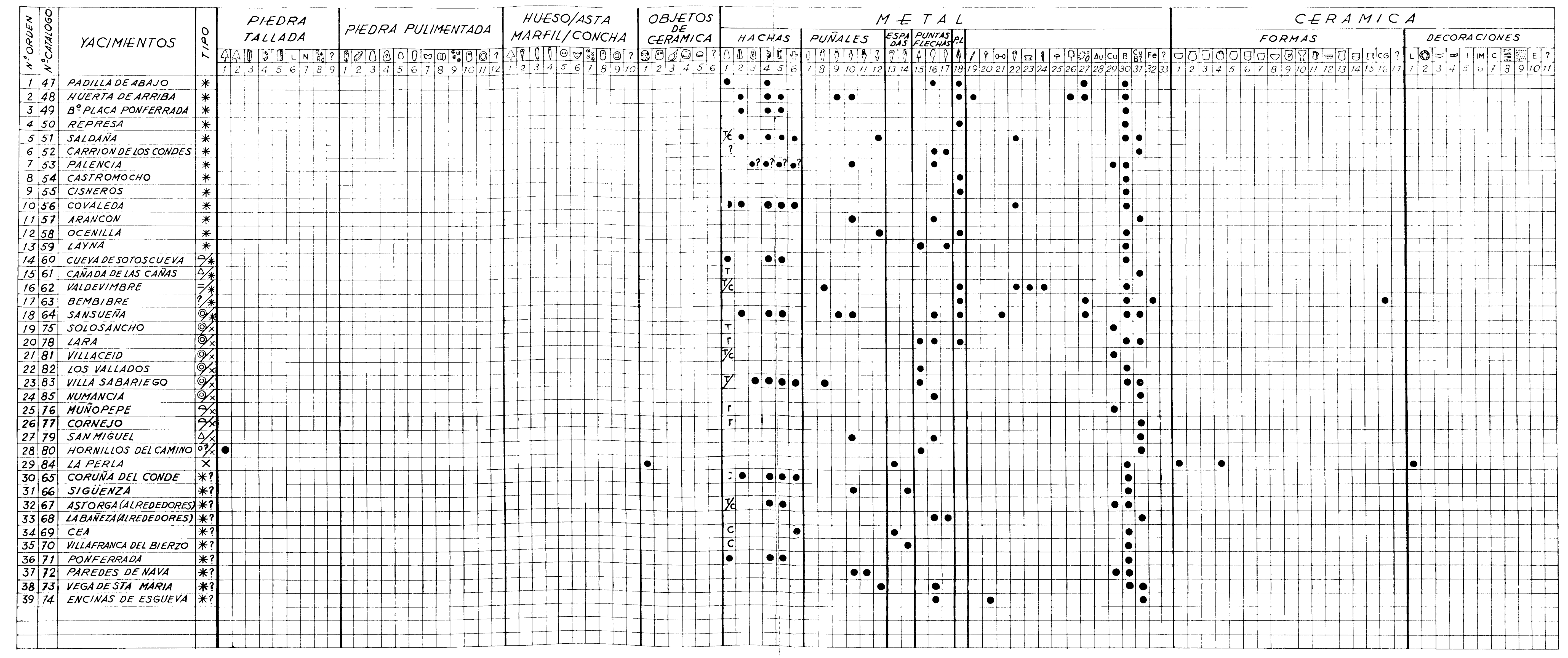




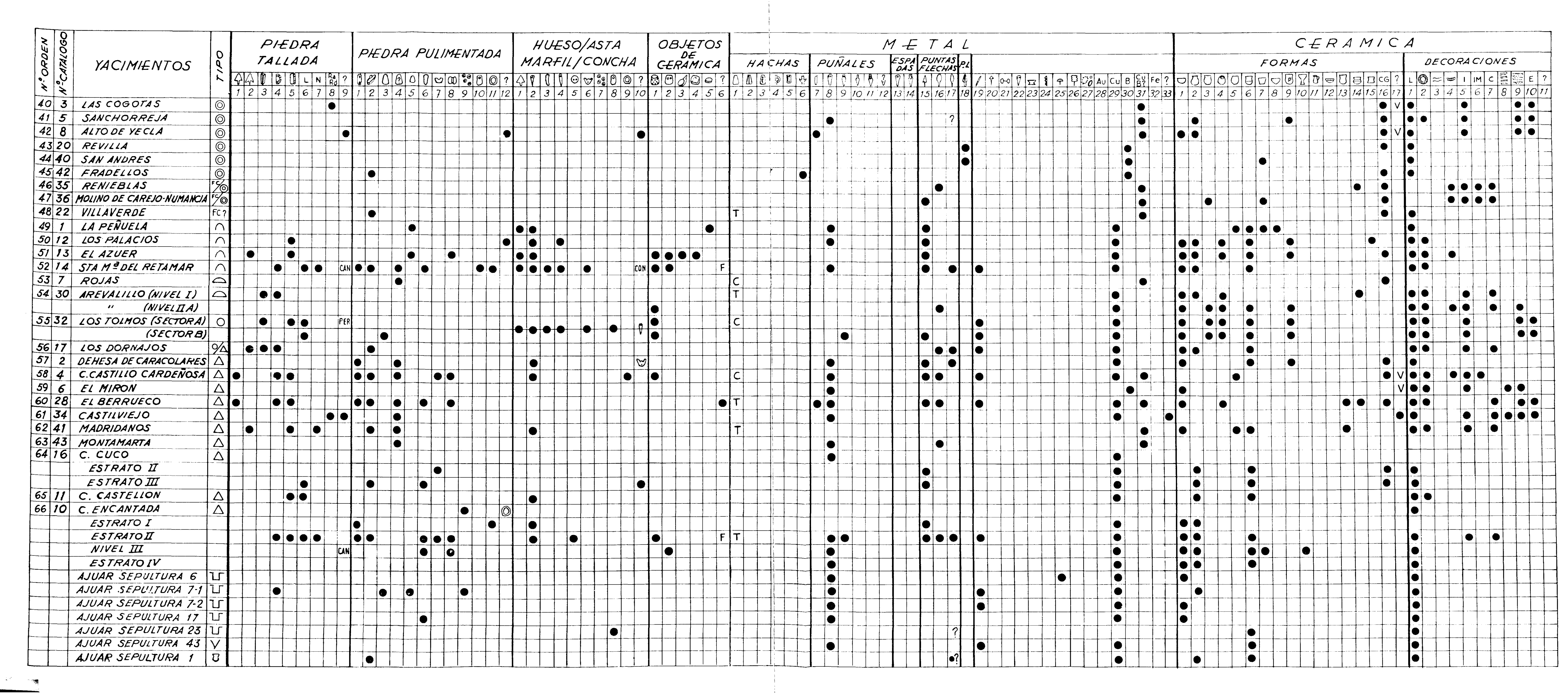




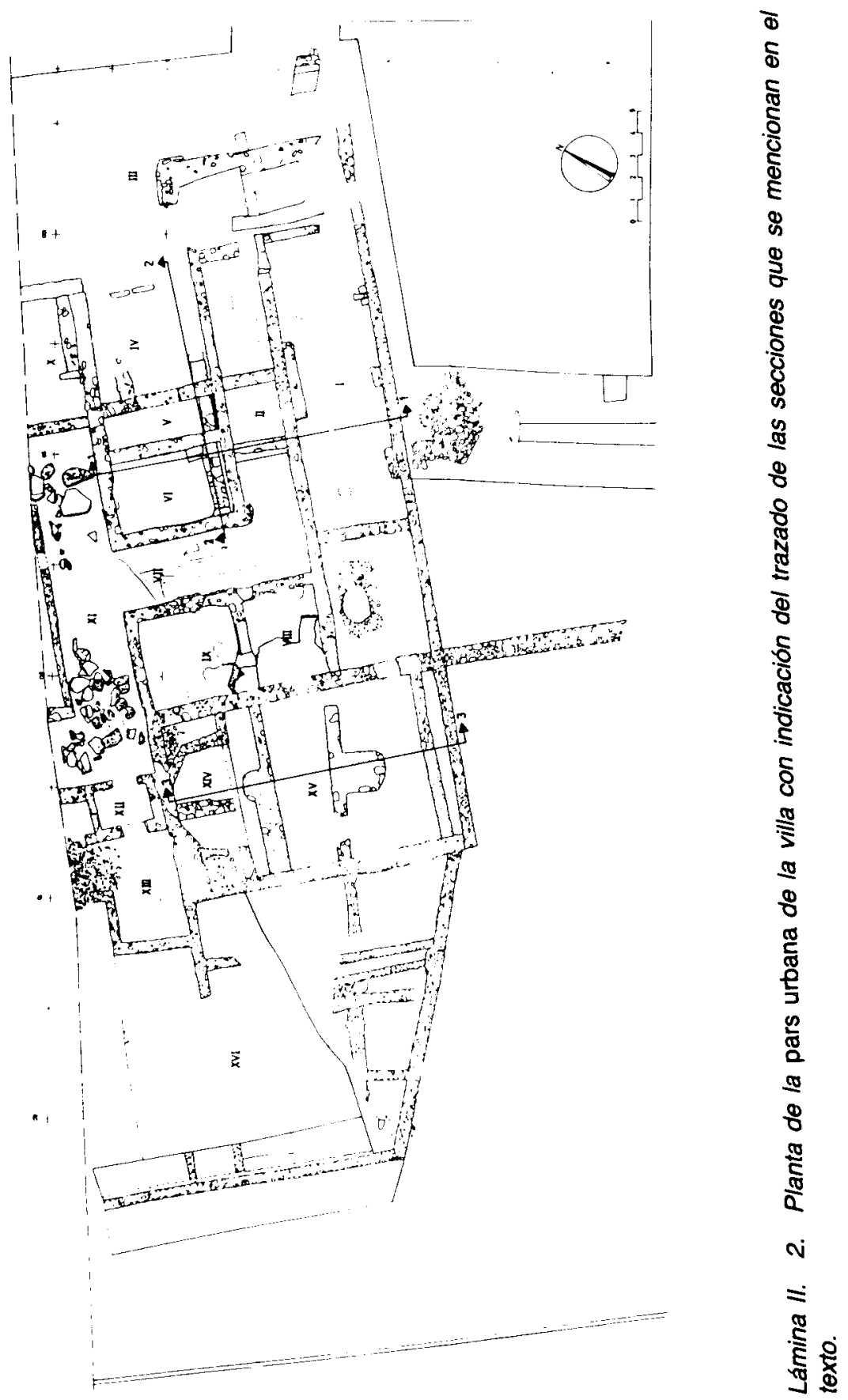


expuestos en nuestro anterior articulo, y que muy pronto podremos comprobar mediante procedimientos geologicos ${ }^{11}$. Esta serie de intervenciones nos proporcionó una idea aproximada de las diversas etapas del desarrollo de la villa. No obstante, careciamos de los datos precisos para poder analizar cada uno de sus elementos, desde la fundación hasta el abandono. Por esta razón, en 1989, después de llevar a cabo los trabajos que aseguraban una solución urbanistica satisfactoria para la conservación de Darró, los esfuerzos se centraron en el conocimiento detallado de la evolución de los restos romanos (de los ibéricos ya teníamos una secuencia minimamente ilustrativa), para lo cual se llevó a cabo una serie de sondeos concretos en la pars urbana de la villa.

\section{LAS ULLTIMAS EXCAVACIONES}

Teniendo en cuenta el interés que han revestido los últimos sondeos citados, empezaremos por describirlos. De esta manera podremos tener un ejemplo de la estratigrafía-tipo que proporciona la explotación agricola romana, y al tiempo su evolución cronológica. Como los medios de que disponiamos para llevar adelante esta excavación eran bastante limitados, tratamos de intervenir en lugares sintomáticos que pudieran dar resultados extrapolables al resto del conjunto con la mínima posibilidad de error (que lógicamente siempre existe).

En consecuencia, se escogieron los pasillos $\mid$ y $\mathrm{II}$, el primero puesto al descubierto y excavado parcialmente por Arribas, y el segundo localizado por nosotros; las habitaciones IV, $V$ y VI, descubiertas en 1986; y los ámbitos XIV y XV, muy afectados por los trabajos de los años cincuenta, pero situados en un punto interesante y dotados de un carácter "noble» en relación al resto de las estancias conocidas.

A continuación expondremos el desarrollo de los trabajos en cada uno de los sectores citados y después presentaremos una sintesis de las conclusiones obtenidas. Hemos de advertir que para hacer más sencilla la exposición se han suprimido las alusiones directas a las diferentes unidades estratigráficas aparecidas, y se ha utilizado una nomenclatura convencional en la que todas las u. e. de un momento determinado se nombran con una misma letra que indica su etapa cronológica.

" Lopez Mullor. Fierro. 1988 C. 
1. El pasillo / (láms. III.1, IV.2)

El estrato superficial de este sector (horizonte F), como el de todo el resto de la pars urbana excavado hasta el momento, era una capa formada en la Edad Moderna, seguramente hacia principios del siglo XVII, cuando toda esta zona del yacimiento se utilizó para el cultivo de la viña. La mayoría de las cerámicas y monedas que se han encontrado son de aquella época, aunque lógicamente también haya intrusiones de la Edad Contemporánea, pues los campos estuvieron en uso hasta hace poco (seguramente se abandonaron en los años cuarenta de nuestro siglo) '?

Esta capa de arenas y limos no tenía una potencia considerable y cubría directamente el horizonte más tardío del yacimiento que se conservaba (E), el cual correspondia a los restos del hundimiento de las paredes y la cubierta de la residencia romana. Debe señalarse que este segundo nivel también fue perturbado por las labores agricolas y, por ejemplo, son evidentes las marcas del arado en los pavimientos de opus signinum de las habitaciones VIII y IX, o bien las numerosas teselas aparecidas dentro del estrato de abandono de la estancia IV o en el mismo nivel del pasillo I.

Estas teselas, que en ciertos casos eran verdaderos trozos de mosaico policromo de un longitud máxima de $20 \mathrm{~cm}$, presentan un problema de interpretación, al haber aparecido mezcladas con los demás componentes del estrato $B$, sin ningun tipo de preparación, y en posiciones muy diferentes: horizontalmente, boca abajo, inclinadas, etc. Sabemos que no pueden corresponder al último pavimento del ámbito I - o del IV en su caso-, porque este suelo apareció perfectamente sellado por el estrato de abandono que describimos. Una vez descartada esta posibilidad, se podría pensar que fueron arrastradas desde su posición original por el cultivo moderno, pero las habitaciones de los alrededores, como veremos (infra: II.1, II.2), no presentan señales de haber poseido mosaico. Una tercera posibilidad, bastante más especulativa, es la existencia de un suelo de este tipo en la primera planta de la casa. Esto deberá comprobarse con nuevos trabajos, pero de momento no dudamos que la villa tuvo un piso elevado, teniendo en cuenta los restos de derrumbamiento encontrados en el ámbito XI (lám. II.2). Se trata de un importante número de bloques de opus signinum caídos en desorden sobre el suelo de la última fase y mezclados con el estrato de abandono, compuesto de ta-

Sobre la activitad vitivinicola en Vilanova: ViRELLA, 1978. 

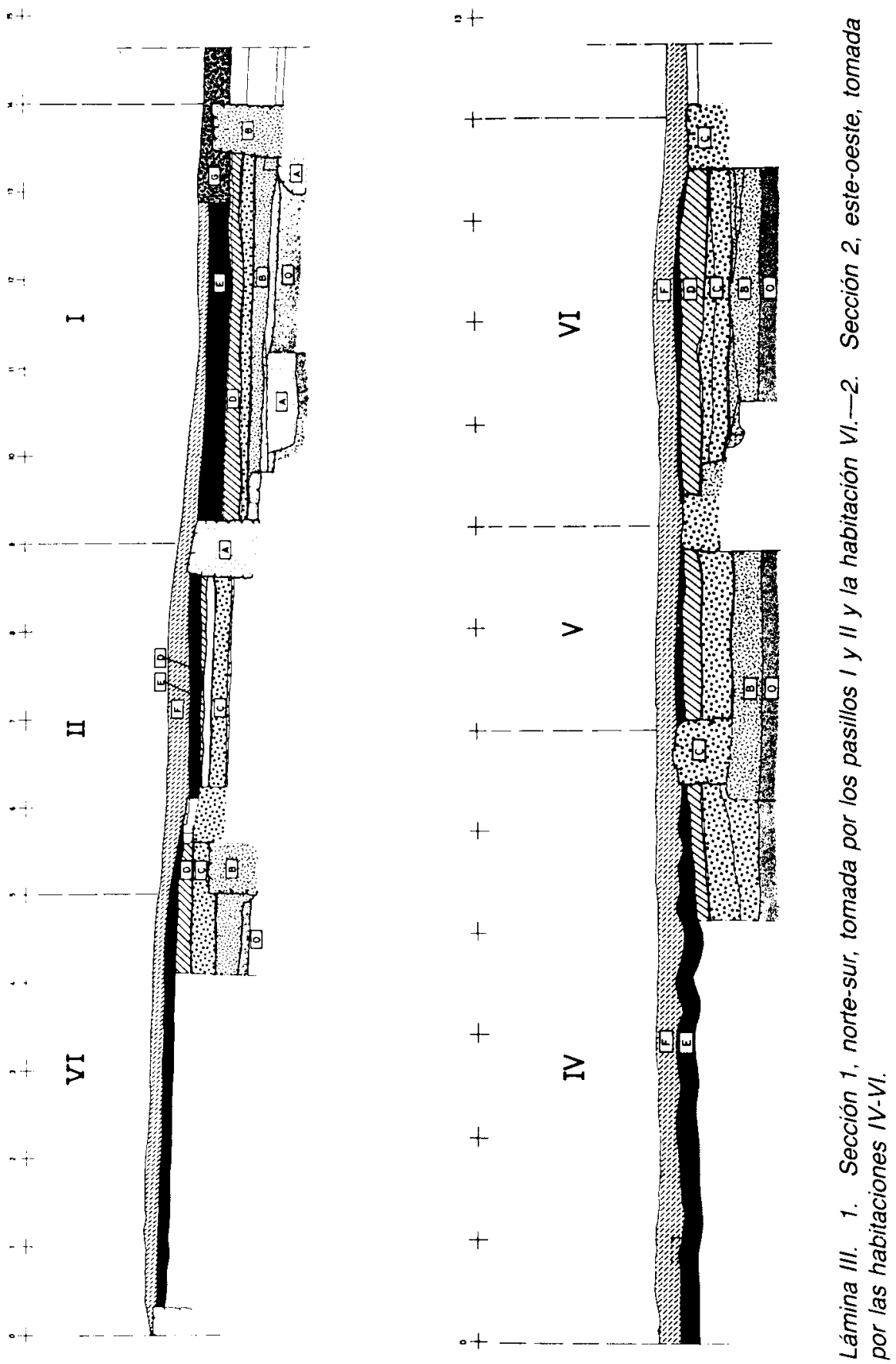
pial, restos de vigas, estuco, etc.). Falta saber si este piso se hallaba circunscrito al perímetro del atrio o peristilo -que según nuestras hipótesis podría encontrarse en el ámbito XVII- o bien se extendia por todo el cuerpo principal de la vivienda. Una última posibilidad, quizá la más verosímil después de todo, es que los mosaicos procedan de esa misma zona porticada, y que se destruyeran y esparcieran al construirse el ferrocarril en 1880-1881, teniendo en cuenta la mínima potencia del estrato de abandono en este sector a diferencia de la zona donde se halló el signinum troceado, protegida por un muro de contención del siglo XVII (infra: II.4).

Volviendo al hilo de la exposición, se ha de añadir que el horizonte $E$ se entregaba sin cubrirlas del todo a las dos paredes que delimitaban el corredor ( $A$ al norte y $B$ al sur). En cuanto a la última, esta posición física debemos intuirla, ya que el muro fue puesto al descubierto por el profesor Arribas, y nosotros sólo hemos encontrado su trinchera rellena de tierras removidas $(G)$.

La cronología del estrato $E$ se puede situar a finales del siglo IV o principios del $v$. Es la misma fecha del pavimento que apareció a continuación y de su preparación (D). Dado que el horizonte $E$ estaba formado por materiales de construcción, podemos deducir que la última etapa de uso del ámbito I empezó en la fecha citada, y que los materiales proceden de la superestructura del edificio, pero no podemos fijar el momento de su abandono, pues la cúspide del pavimento $D$ se encontró completamente limpia. Ello hace pensar que la villa sufrió un largo proceso de degradación, cuya cronología analizaremos más adelante (infra: III.1).

El siguiente horizonte aparecido (C) lo formaban otro pavimento y su preparación. El análisis de los materiales que contenían nos inclina a situarlo hacia el 350 d.C. Como veremos (infra: III.2.3.), se trata de un momento de cambios en la compartimentación de la residencia, pero aquí sólo se aprecian por la aparición de un nuevo suelo. Seguidamente se encontraron otro pavimento y sus correspondientes preparaciones (B). Todas estas unidades pudieron datarse en el 220/240 d.C., y el interés de tal cronologia estriba en señalar la fundación de la pared de mediodia del corredor $(B)$, puesto que el pavimento cubría su banqueta y las preparaciones se le entregaban. Por consiguiente, esta fecha indica la creación del pasillo I, es decir, la colocación de la fachada de la pars urbana en el lugar donde permaneció hasta el abandono de la villa.

Los estratos del horizonte B también evidenciaban que hacia el $220 /$ 240 quedó anulada una serie de interesantes estructuras, cuya fecha de construcción debe situarse hacia el primer cuarto del siglo II, pues se 
relacionaban con el nivel $A$. En primer lugar deben citarse unos pilares (lám. V.1), los cuales creemos que sustentaban un pórtico, asociado a la entrada principal y al empedrado descubierto en 1986 (infra: IV.4, lám. (11.2). En segundo lugar, dos paredes trazadas en dirección norte-sur descubiertas en 1989 (lám. V.1), cuya situación se ha de asociar con el cierre oriental del pórtico, formado tal vez por un cuerpo sobresaliente. Además se ha de destacar la presencia de un banco corrido adosado por el lado sur a la pared septentrional del pasillo (A). Sus respectivas fundaciones eran contemporáneas del pavimento $A$, que se descubrió a continuación.

Por fin se localizó una serie de capas alternas de gravas y arenas (0), que ya habiamos excavado en 1986 y pueden datarse en los siglos ॥I a.C. Lógicamente son anteriores a la villa y han de relacionarse con la ocupación ibérica ${ }^{13}$.

\section{El pasillo // (láms. III.1, IV.2)}

Apareció despues de haberse extraído el estrato superficial $F$, que ya hemos descrito antes. Al norte estaba limitado por los muros meridionales de las habitaciones IV (C), V (D) y VI (C). Todos ellos se hallaban perfectamente alineados, pero asi como el primero y el último presentaban el aparejo corriente en la mayoría de las paredes de la residencia, de mampostería unida con bastante cal y cubierta de estuco - en este caso blanco-, el segundo muro era de piedras unidas con barro, lo que, junto con su posición física, indicaba que se trataba tal tapiado de un antiguo acceso. Al sur se encontraba el lienzo A, que ya hemos visto en el párrafo anterior.

La excavación continuó con el descubrimiento del nivel $E$, que se entregaba y casi cubría a todos los muros citados. Se trataba de un estrato idéntico al que hemos designado con la misma letra en el pasillo $\mathrm{I}$, con numerosos restos de derrumbamiento $y$, como aquél, se fechaba a finales del siglo IV o principios del $\mathrm{V}$. Se apoyaba directamente sobre el horizonte $\mathrm{D}$, formado por un pavimento y su preparación. Ambas unida-

13 Lopez Mullor, Fierro, $1988 \mathrm{c}$. 
des eran de la misma época que los vestigios de tapial, vigas, estuco, etcétera, del nivel anterior. Seguidamente se localizó otro suelo con una capa previa de nivelación (C/D), situable entre el 350 d.C. y finales del siglo IV o comienzos del $\mathrm{V}$.

Acto seguido se descubrió un tercer suelo al que precedian diversos estratos de relleno (C) fechados hacia el 350 d.C. La preparación más profunda cubría y se entregaba a una serie de muros paralelos trazados en dirección norte-sur $(B)$, que se encontraron muy deteriorados, pero con la entidad suficiente como para advertir que ocupaban toda la anchura del pasillo. Por otra parte, debe señalarse que la colocación del suelo $\mathrm{C}$ coincidió con la fundación de las paredes meridionales de las habitaciones IV y $V(C)$. Despues aparecieron las unidades del nivel B, relacionadas con la compartimentación anterior a la apertura del pasillo II. Por ahora sólo sabemos que han de asociarse con los muros paralelos mencionados antes (B) y que pueden fecharse en el 220/240 d.C. Al llegar a esta cota hubo que detener la excavación porque, debido al gran número de restos aparecidos, careciamos de espacio para poder continuarla con garantías.

\section{Las estancias IV, $\vee y$ VI (láms. III.2, IV.2)}

Como los sondeos realizados solamente afectaron al tercio meridional de los ámbitos enunciados y se practicaron alineados los describiremos conjuntamente. Además, los resultados obtenidos en todos ellos se relacionan entre si.

En un principio se encontró el estrato moderno $F$. Una vez excavado empezaron a aparecer los muros que delimitaban las distintas habitaciones. Todas ellas, como veremos, databan de la fase $\mathrm{C}$, a excepción de la $V$, cuyo cierre meridional era del momento $D$. Además, la habitación IV no tenía aparentemente pared alguna a Levante, aunque se apreciaron los restos de un umbral (de la etapa E): la presencia de una estructura de este tipo puede sugerir que el muro de este lado estaba tan arrasado que no se llegaba a ver, como pasa en las paredes del ámbito III, donde se han descubierto algunos paramentos mediante la impronta de su estuco. Se ha de añadir que en el centro de la medianera de las habitaciones IV y $V$ se advertia un pequeño paso muy degradado pero perceptible, lo que indicaba que, a lo largo de la última etapa de la villa (D) estos recintos se comunicaban. 
Después del estrato $F$ se localizo en las tres estancias el horizonte $E$. Se trataba del conocido nivel de derrumbamiento, fechable a finales del siglo Iv o principios del $v$. A continuación se descubrieron los pavimentos correspondientes a la etapa D. El de la habitación VI era de cal muy degradada y los otros dos de opus signinum. Todos ellos databan de finales del siglo $\mathrm{i}$ o comienzos del $\mathrm{v}$, y se apoyaban directamente en otros suelos, esta vez de hacia el 350 d.C. (fase C), colocados sobre preparaciones contemporáneas.

Se ha de destacar que este último conjunto de niveles se asociaba a la fundación de las habitaciones IV, V y VI. Al mismo tiempo ocultaba los restos de la primera compartimentación de esta zona que tenía un trazado parecido al descrito hasta ahora pero no idéntico (lám. V.2). En la sección que nos sirve de guia podemos observar que en la habitación $\mathrm{VI}$ el pavimento $\mathrm{C}$ cubre un muro correspondiente a una estancia del trazado más antiguo (B) sobre el que también se apoya la pared de Poniente de la habitación VI. Esta estratigrafía tan clara no se aprecia en la habitación $V$, pues el dibujo del corte no afectó ninguna de las estructuras mas antiguas, que quedaban algo desplazadas. En la habitación IV la situación es semejante pero en este caso se debe al considerable arrasamiento de la pared correspondiente de la etapa B y a la presencia de un testigo.

Cuando continuó la excavación se localizaron los pavimentos que habían ocupado los ámbitos descubiertos debajo de IV-VI, seguidos de unas preparaciones bastante potentes. Todo este conjunto de la fase B puede situarse hacia el 220/240 d.C., gracias a los materiales. Seguidamente apareció la capa de arenas de época tardorrepublicana $(O)$, que se encuentra habitualmente en el subsuelo de la residencia, y que en este lugar se reutilizó como suelo durante el momento $A$.

Los datos más importantes proporcionados por estos sondeos hacen referencia a la fundación y el desarrollo de las habitaciones. De esta manera ahora sabemos que las estancias IV, $\mathrm{V}$ y $\mathrm{VI}$ se construyeron hacia el 350 de la Era (C) y experimentaron cambios en torno a principios del siglo $\vee(D)$, el más importante de los cuales fue la pavimentación con opus signinum de los dos ámbitos de Levante. Entonces también se puso el tapiado a Mediodía de la habitación $V$, comunicándose al tiempo ésta con la IV. En cuanto al abandono, no tenemos indicios para situarlo en el tiempo porque, como se sabe, los pavimentos aparecieron totalmente limpios. Sin embargo, esta misma circunstancia evidencia que no tuvo lugar súbitamente. 
Por otra parte, sabemos que antes de que se construyesen las habitaciones citadas ya existian otras con un trazado similar, pero que de momento no conocemos completo. Estas primeras habitaciones tuvieron un uso breve, ya que se fundaron hacia el 220/240 (B) y se abandonaron el ca. 350 (C). Al no haber descubierto ninguna estructura anterior antes de llegar a las arenas republicanas de la base podemos pensar, al menos como hipótesis, que desde la época de Trajano (A), cuando se erigieron el muro que limita al norte del pasillo I y las otras estructuras localizadas en el subsuelo del corredor, este sector se encontraba libre de construcciones. Quizá se trataba de un patio (por ahora es imposible establecer si era un atrio, un peristilo o alguna estructura de este tipo) similar al que se insinúa al norte del ámbito XI, situado probablemente bajo la vía del tren, y que tal vez será del siglo iv (C), aunque se ha de abrir un sondeo para averiguarlo.

El oecus, ámbitos XIV y XV (lám. IV)

Este recinto se descubrió o, mejor dicho, se redescubrió el año 1986, pues ya habia sido parcialmente excavado durante las campañas dirigidas por el profesor Arribas (lám. 1.2). Entonces se exhumó casi la totalidad de los estratos de abandono de la exedra (XIV) y del aula (XV). Además se abrió una trinchera para destapar el cierre meridional (B), se siguió el trazado del resto de las paredes perimetrales (C) y hasta se descubrieron otras que habia en el subsuelo (A), una de las cuales, situada en el centro del ámbito, se desmontó parcialmente. Con todo, al final de aquellos trabajos no se llegó a conclusiones definitivas sobre la función, la cronologia y la evolución del área que nos ocupa ${ }^{14}$.

Además se ha de recordar que las tierras que cubrían el oecus, como las de todo el resto del yacimiento, estuvieron dedicadas al cultivo de la viña durante varios siglos, y en este caso concreto la actividad agrícola influyó considerablemente en la conservación de las ruinas. La modificación más evidente consistió en la formación de una terraza que, al empezar la excavación, ocupaba los ámbitos XII, XIII y buena parte del XIV y XV; estaba limitada por un muro que cortaba en diagonal los sectores XIV y XVI, y a través de XI se adentraba bajo la vía del tren. Pensamos que las tierras que se removieron para formar la citada terraza

${ }^{14}$ ARRIBAS, $1959: 325-328$. 


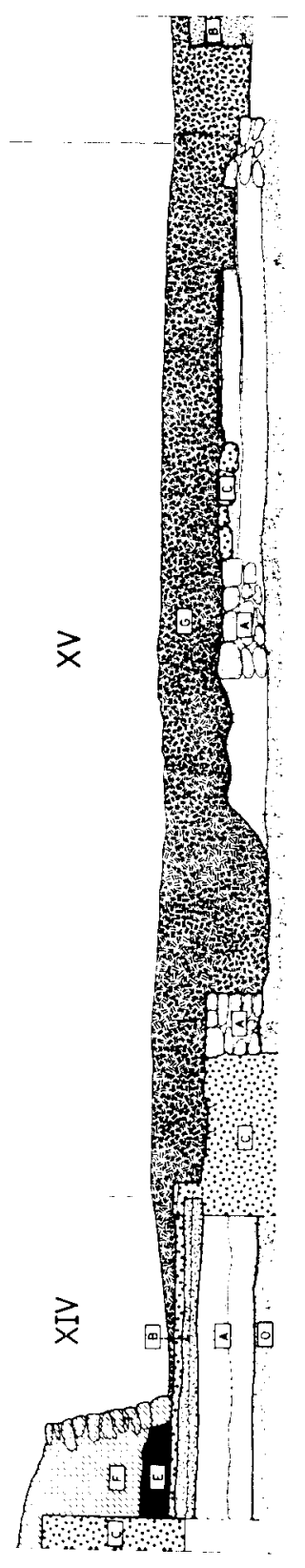

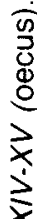

है 


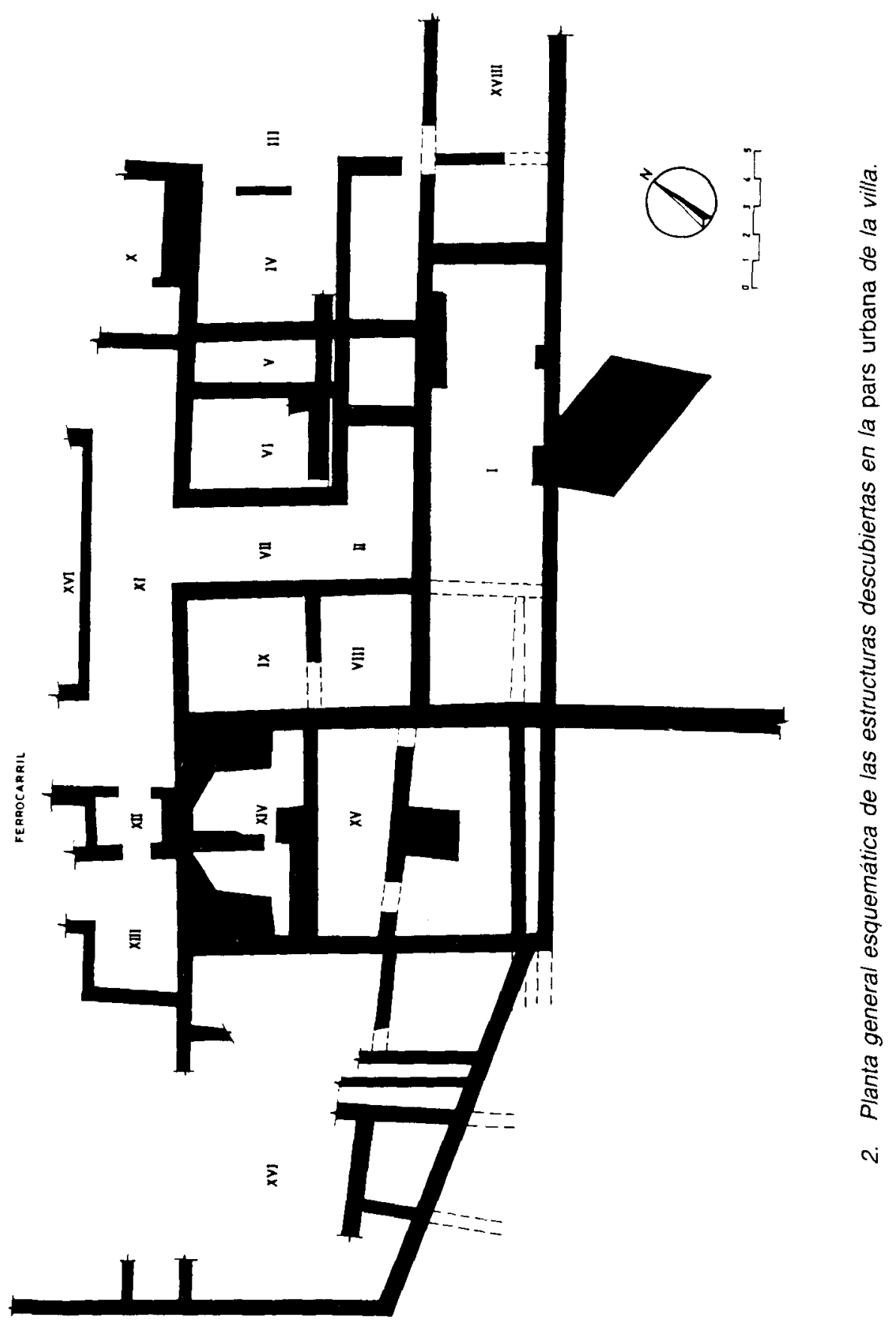


se echaron al otro lado de la pared que limita la pars urbana a mediodía (B). Así se obtuvieron dos superficies aptas para el cultivo, una más alta que la otra.

Esta hipótesis, además de por la presencia del muro de contención referido $(F)$, se confirma por la considerable altura de las ruinas descubiertas al norte del paramento, por la mayor potencia de la estratigrafia en aquel lugar, por la composición de los sedimentos que hay al sur, extramuros de la residencia, en los que hemos localizado abundantes piedras.

Después de formular esta consideración previa pasaremos a describir la estratigrafía localizada en estos ámbitos y lo haremos mediante la sección norte-sur tomada prácticamente por el eje de las construcciones (lám. IV.1). En este corte se puede ver que el estrato superficial queda muy bajo. Ello es lógico si consideramos que no se trata del horizonte $F$, descubierto en otros lugares, sino de la capa que se colocó una vez concluidas las excavaciones de los años 50 (G). Por consiguiente, los niveles de derrumbamiento $(E)$ sólo se conservaron en un pequeño sector dentro del ábside, protegido por el muro de la terraza moderna $(F)$. Todas estas capas contenian diversos restos de material de construcción, como adobes, tejas y tapial, pero en una de ellas se encontraron fragmentos del opus formaceum y estuco de color blanco procedentes de la bóveda que coronaba el ábside. Estos estratos, aunque no proporcionaron demasiado material, se pueden fechar entre principios del siglo III y finales del IV - un arco extremadamente amplio, pero que iremos precisando gracias a la posición física de las estructuras-(infra: fase B).

A continuación apareció el pavimento de la exedra formado por una fina capa de cal y dotado de una preparación que se entregaba al escalón terminal de la cabecera (C). Estos niveles no dieron suficiente cerámica para establecer su dotación definitiva pero poseemos la cronología inmediatamente inferior $(B)$, cifrada hacia la primera mitad del siglo 111 , lo que proporciona un terminus post quem. Esto, unido a la mencionada fecha de los estratos de derrumbamiento (supra: E), nos hace pensar que el oecus se construyó dentro de la etapa cronológica $\mathrm{C}$, cuyo inicio hemos establecido hacia el 350 d.C. El estrato que da el t.p.q. de estos acontecimientos también tiene la particularidad de que se le apoyan los muros y el escalón de la exedra.

Seguidamente se descubrió un nuevo horizonte (A) compuesto por dos capas de relleno. A través del material se pudo situar en la primera mitad del siglo II y descansaba sobre las arenas tardorrepublicanas (0) que hemos encontrado en otros lugares del yacimiento. Además se entre- 
gaba a un muro trazado en dirección norte-sur, situado casi en el eje de la cabecera (láms. II.2, IV.2), el cual habia sido amortizado por el estrato $\mathrm{B}$ y se apoyaba en las mismas arenas que el horizonte $\mathrm{A}$. La excavación de la exedra la detuvimos momentáneamente en este estrato ibérico $(0)$, y los trabajos se extendieron al aula. En este ámbito, después de la capa superficial de hace algunos años $(G)$, se encontró una mancha de cal en un punto muy concreto, interpretándose como el único resto que quedaba del pavimento (C). Su preparación también se localizó en un lugar bastante pequeño. A continuación se descubrió un estrato de considerable potencia (A) que cubría directamente las arenas republicanas. En su seno se distinguieron varias bolsadas que podian presentar como componentes dominantes carbones o arcillas. Debe destacarse que este horizonte contenia muchos fragmentos de ánforas romanas manufacturadas en la alfareria de la "zona 2", mezcladas con trozos de ladrillo refractario y paredes de horno. Además el estrato que describimos se entregaba a tres muros que aparecieron en el subsuelo de la estancia, construidos en seco, paralelos y trazados en direccion este-oeste $(A)$.

Estos paramentos, según comprobaremos (infra: III.2.1), habian formado parte del primer trazado de la residencia que conocemos; funcionaron durante la segunda etapa y fueron arrasados al erigirse el oecus. Es muy posible que las paredes del aula cortasen el estrato de relleno (A) que se asociaba a los muros descritos pero los efectos de la excavación de Arribas nos ha impedido comprobarlo. No obstante, a Mediodía del aula se conservan los restos de un conglomerado de piedras $(C)$ que podía haber sido la preparación de un pavimento noble, ahora totalmente desaparecido. La posición de estas piedras es importante porque se apoyan sobre el estrato de relleno $A$ y aprovechan la cúspide de uno de los muros del mismo momento. Tal vez la zona más elevada del paramento sirvió como escalón, lo que indicaría que el ábside estaba precedido por dos gradas.

Por lo que se refiere a la apariencia y la función de los ámbitos XIV y XV durante la época en que funcionaron juntos, de lo que hemos dicho hasta ahora se deduce que se trataba de una aula (XV) encabezada por un ábside pentagonal o exedra (XIV). Todo el recinto se puede interpretar como un oecus, teniendo en cuenta su situación y características especiales. La observación de las estrias diagonales que presentan sus paramentos - que no se dan en otras estructuras de la misma fase- hace pensar que estaban recubiertos por un revestimiento más suntuoso que el estuco «normal», pero no hemos encontrado ningún vestigio del mismo in situ. Del pavimento no sabemos demasiado, pues sólo poseemos una mancha de cal; a lo mejor esta cal era el lecho de un suelo más elabo- 
rado o lujoso. En cuanto a la cubierta, la exedra debería tener una bóveda, posiblemente de abanico, revestida de estuco interiormente. En el caso del aula parece que era una estructura de madera apoyada sobre columnas, de las que Arribas encontró dos capiteles y tres basas, muy semejantes a los hallazgos casuales del mismo tipo realizados en 1880 , en una zona incierta.

Las estructuras del momento más antiguo de la residencia que conocemos hasta hoy (A, fundadas hacia el primer cuarto del siglo 1 ) son ciertamente interesantes en el sector del oecus. En primer lugar, se trata de tres paredes paralelas, erigidas de este a oeste dentro del ámbito XV, las cuales debieron formar parte del cuerpo occidental de la casa. Todas ellas tienen continuidad fuera de los límites actuales del aula. La del centro la conocemos bien gracias a las excavaciones que hemos llevado a cabo en los sectores I y II, donde representó el papel de fachada principal, y también sabemos su trazado hacia el oeste gracias a los trabajos de Arribas (lám. V.1, Mediodía del ámbito XVI). Sobre las otras dos sólo podemos proponer hipótesis: el lugar donde deberia continuar la del norte todavia no se ha excavado, y la del sur parece que sigue un buen trecho pero tampoco hemos podido comprobarlo hasta la fecha. Parece que los tres lienzos se utilizaron a lo largo de las fases A y B, y fueron anulados con la construcción del oecus.

En segundo lugar, en el subsuelo de ábside (XIV), apareció otro muro, esta vez construido de norte a sur. Tal vez enlaza con la pared más septentrional de las que hemos visto en el párrafo anterior, pero un testigo estratigráfico -el de la plataforma de piedras delante de la exedra- nos ha impedido comprobarlo. De todas maneras, es muy probable que ambos paramentos haya constituido los límites meridional y occidental de una habitación cerrada a Levante por la pared del actual ámbito VII y, al norte, por el largo muro donde se entregó la cara septentrional de la exedra (la excavación ha demostrado que, al construirse la cabecera, este paramento ya existía y el ábside se le "cosió"). En cuanto al cierre meridional del aula (datado en el momento B), la observación de la planta general (láms. II.2, IV.2) muestra su continuidad respecto al lienzo que dio lugar a la formación del corredor o pasillo I, y la construcción de esta pared se ha de relacionar con una remodelación importante de la pars urbana que analizaremos en el capitulo de conclusiones (infra: III.2.2). No obstante, debe destacarse que este paramento continuó en uso hasta el abandono de la villa, pues se reaprovechó al construirse el oecus. 


\section{CONCLUSIONES PROVISIONALES DE LA INVESTIGACIÓN EN LA PARS URBANA}

\section{Cronología}

El estudio de los materiales de las últimas excavaciones ${ }^{15}$ ha proporcionado algunos datos importantes. Entre ellos la evolución cronológica del sector de la residencia donde hemos trabajado. En sintesis, y según la nomenclatura convencional que hemos utilizado, es la siguiente:

0 . Preexistencias de la última etapa de ocupación ibérica: siglos II-I a.C.

A) Fundación de las estructuras más antiguas halladas hacia el primer cuarto del siglo ॥ de la Era, quizá durante el imperio de Trajano.

B) Remodelación muy importante de ca. 220/240, que dio lugar a los rasgos esenciales de las ruinas descubiertas.

C) Nuevos cambios hacia el 350 que casi determinaron la planta actual de los restos.

D) Modificaciones de detalle a finales del siglo IV o principios del $\mathrm{V}$.

E) Abandono en una fecha incierta, como mínimo en el siglo $v$ avanzado o en el vi.

F) Utilización agrícola medieval y sobre todo moderna y contemporánea que se hizo intensiva desde el siglo XVIII.

G) Excavaciones de los años cincuenta de nuestro siglo.

De momento, el principal problema cronológico es la fecha de abandono. Los estratos superficiales son muy débiles o han desaparecido por la acción de los cultivos. También, en los pocos lugares donde existe una potencia suficiente, se observa que los pavimentos están casi completamente limpios, y las únicas piezas presuntamente contemporáneas del último momento consisten en cerámicas grises a torno lento, difícilmente clasificables. Otro indicio es la aparición de sigillatas africanas muy tardías - que pueden llegar al siglo vi-en ciertos lugares de la pars rustica (infra: IV.1.2).

Este trabajo to daremos pronto a conocer en conjunto, pero de momento se han estudiado diversas clases de material: Lopez Mullor, Ferrer Marti, Mormeneo, 1981; Lo. pez Mullor, Ferrer Marti, 1982 d; Lopez Mullor, 1980: Idem, 1986; Idem, 1989 a; Idem. 1989 b; CluA, 1989; GuMA, 1990. 
Además, durante la excavación se ha comprobado que el derrumbamiento de las ruinas fue muy lento y antes de que se produjese habian sido saqueadas: faltan los sillares de las esquinas, las piedras de un buen número de muros, etc. Todo ello hace pensar que, por ahora, el abandono se puede situar en un momento avanzado del siglo $v$ o ya dentro del Vl, según indican las cerámicas citadas.

En cuanto a la utilización agrícola de los predios durante las edades Moderna y Contemporánea no nos extenderemos aquí en la descripción de las estructuras inherentes o de su función, pero debe destacarse que durante los trabajos se han encontrado varios pozos, como el del extremo occidental del pasillo I (lám. II.2), o muros de contención para formar terrazas, como por ejemplo el que cortaba en diagonal la mitad oeste de la residencia romana.

\section{La distribución interior}

Por lo que se refiere a las estructuras antiguas halladas, ahora sólo podemos analizar con cierto detalle las más superficiales, que funcionaban desde el 350 aproximadamente (C). De todas formas, los sondeos parciales han evidenciado que los muros principales son de los siglos 11 y III (A y B). Por otra parte, nuestras investigaciones únicamente han afectado un sector del área residencial de la explotación agrícola, que podría abarcar algo menos de la mitad meridional del conjunto. Como se sabe, la línea férrea atraviesa esta zona del yacimiento, y todavía no hemos excavado en extensión al norte del ferrocarril ${ }^{16}$.

Por consiguiente, las últimas investigaciones han confirmado y precisado las hipótesis sobre el desarrollo de la pars urbana de la villa, que habiamos propuesto a raiz de los primeros trabajos de $1986{ }^{17}$. De momento no hemos descubierto las construcciones de época augustea, que habrian de asociarse cronológicamente con la alfarería de la «zona 2" (infra: V), pero no descartamos que estén todavia mas cerca de la vía del tren 0 , desgraciadamente, debajo. En todo caso, los hallazgos de cerámica de aquel momento son constantes, tanto en la "zona 1" como en otros lugares del yacimiento. Valga decir que en la "zona 0 " se ex-

16 En 1982 se practicaron algunas catas de prospeccion que afectaron estructuras imperiales. También se realizó una intervención de urgencia cuando se colocaron las tuberias de servicio de la escuela "Llebeig", situada al nordeste del conjunto.

1 Lopez Mullor, Fierro, 1987; Idem, 1988 a; Idem, 1988 b. 
cavaron hace diez años los vestigios de una habitación muy arrasada por las máquinas en 1977, la cual podía fecharse hacia el tercer cuarto del siglo I. Ello indica sin duda una ocupación anterior a los muros más antiguos que hemos encontrado en los sectores excavados en la pars urbana (que, recordémoslo, datan del imperio de Trajano). Tampoco debe olvidarse la localización de una moneda de Tiberio, fuera de contexto, en la propia "zona 0 " ${ }^{18}$, o el relleno de un silo localizado en la misma área, fechado hacia el 60 de la Era.

\subsection{Las construcciones de la época de Trajano (lám. V.1)}

El conocimiento que tenemos del aspecto de la residencia en aquel tiempo es forzosamente parcial, pues las estructuras correspondientes son las más antiguas que hemos hallado hasta ahora y lógicamente ocupan la posición más baja en las estratigrafias. Ello implica que en ciertos lugares todavía no las hayamos localizado. No obstante, empezamos a tener una idea bastante clara de cómo funcionaba la casa entonces. La entrada parece que estaba en el centro del sector donde hemos trabajado últimamente, seguramente algo desplazada. Conducia hasta ella un camino empedrado y estaba precedida por un pórtico sostenido con pilares -que ocupaba el centro del ámbito $1-$. En los lados tenía sendos cuerpos sobresalientes. El de Levante (zona este de I y sur de III) lo conocemos poco porque las ruinas de este lado están muy arrasadas, pero como mínimo sabemos sus dimensiones principales. Del de Poniente tenemos una idea más clara. De momento se distinguen tres estancias alargadas construidas de este a oeste; la meridional ocupaba el tercio sur de XV y XVI, así como el oeste de I; la de en medio comprendía la habitación VIII, la zona central de XV y se adentraba hacia XVI; y las septentrional, menor que las otras, ocupaba el sector IX y la mitad de XIV.

Al oeste de este cuerpo, también se observan vestigios de la compartimentación norte-sur, que indican, como minimo, dos habitaciones más a mediodía del sector XVI, las cuales se prolongan hacia un lugar no excavado, fuera de los límites actuales de las ruinas. El hecho de no haber encontrado ningún vestigio en el subsuelo de los ámbitos IV-VI, detrás de la fachada principal, hace pensar que entonces se trataba de

18 Clua, 1989. 


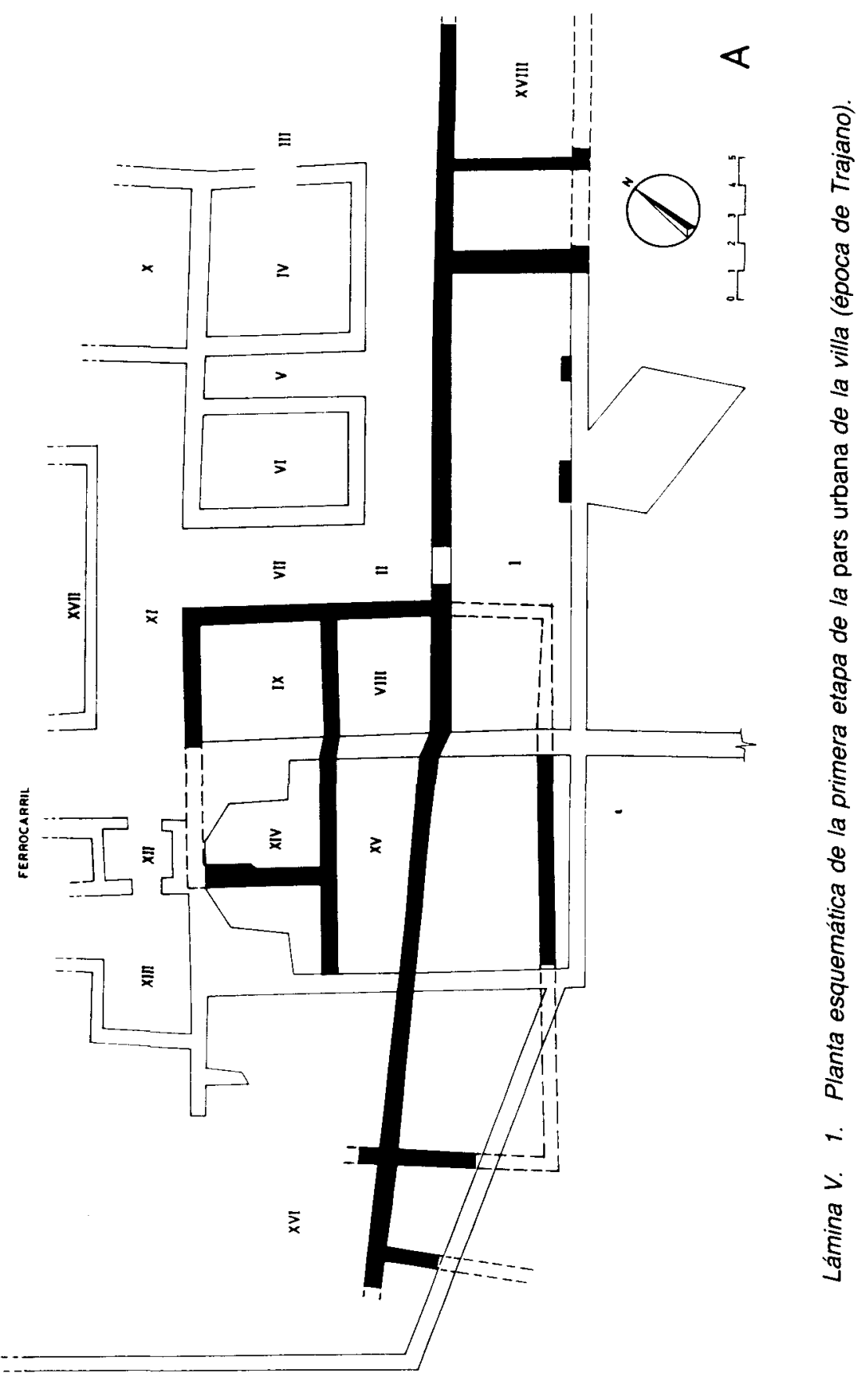


un lugar libre de construcciones, quizá un atrio. Sin embargo, falta la excavación de los niveles más bajos de II, a través de la cual tal vez se pueda reafirmar o matizar esta suposición.

En cuanto al cierre de la vivienda, su extremo occidental lo podemos imaginar gracias a algunas ruinas, cuya cúspide sobresale desde que se extrajo el estrato superficial en 1986 (no se han representado en la planta general, a la espera de poderlas excavar y dibujar completas). Sin embargo, pensamos que la hipótesis presentada en el planta puede ser factible. En el lado oriental las cosas no son tan claras, pues se ha tenido que excavar muy lentamente debido al considerable arrasamiento de los restos, y aún no se han alcanzado los niveles más antiguos. De todas maneras, la forma rectangular del edificio que se insinúa no parece desacertada, asi como el acceso precedido por un pórtico y flanqueado por sendos cuerpos.

Gracias a la epigrafia sabemos algo más de la villa del siglo II; es probable que uno de sus possessores de aquel tiempo fuese $C$. Clodius Aemilianus, personaje conocido en la prosopografía de Tarraco, donde sus parientes ocuparon diversas magistraturas ${ }^{19}$. Nosotros pensamos que Aemilianus es el exponente de la vinculación de Darró con el ager tarraconense ${ }^{20}$. Como también suponemos que la aparición de un cipo en la villa del castillo de Castelldefels, dedicado a $C$. Trocina Synecdemus, magistrado de Barcino, evidencia que aquella explotación formaba para del territorium barcelonés ${ }^{21}$. Esta necesidad de fundamentar la riqueza y el prestigio en la posesión de fincas rústicas, tan bien documentada en el período que nos ocupa, nos sirve para proponer una vez más - en este caso con nuevos argumentos-que el limite entre las áreas sujetas a la respectivas jurisdicciones de ambas colonias debía ser probablemente el macizo del Garraf. A lo mejor esta frontera ya tenía vigencia antes, en tiempo de los íberos, como lo podrían demostrar las producciones cerámicas, muy diferentes a uno y otro lado de la sierra, pero ésa ya es otra cuestión.

\subsection{El trazado del $220 / 240$ (lám. V.2)}

La distribución que se utilizó en esta etapa es un poco más clara para nosotros que la del siglo II, ya que sus ruinas son más superficiales

19 Castellano, 1986.

20 LÓPEZ MULLOR, 1986: 136-137

21 LOPEZ MULLOR (en prensa). 


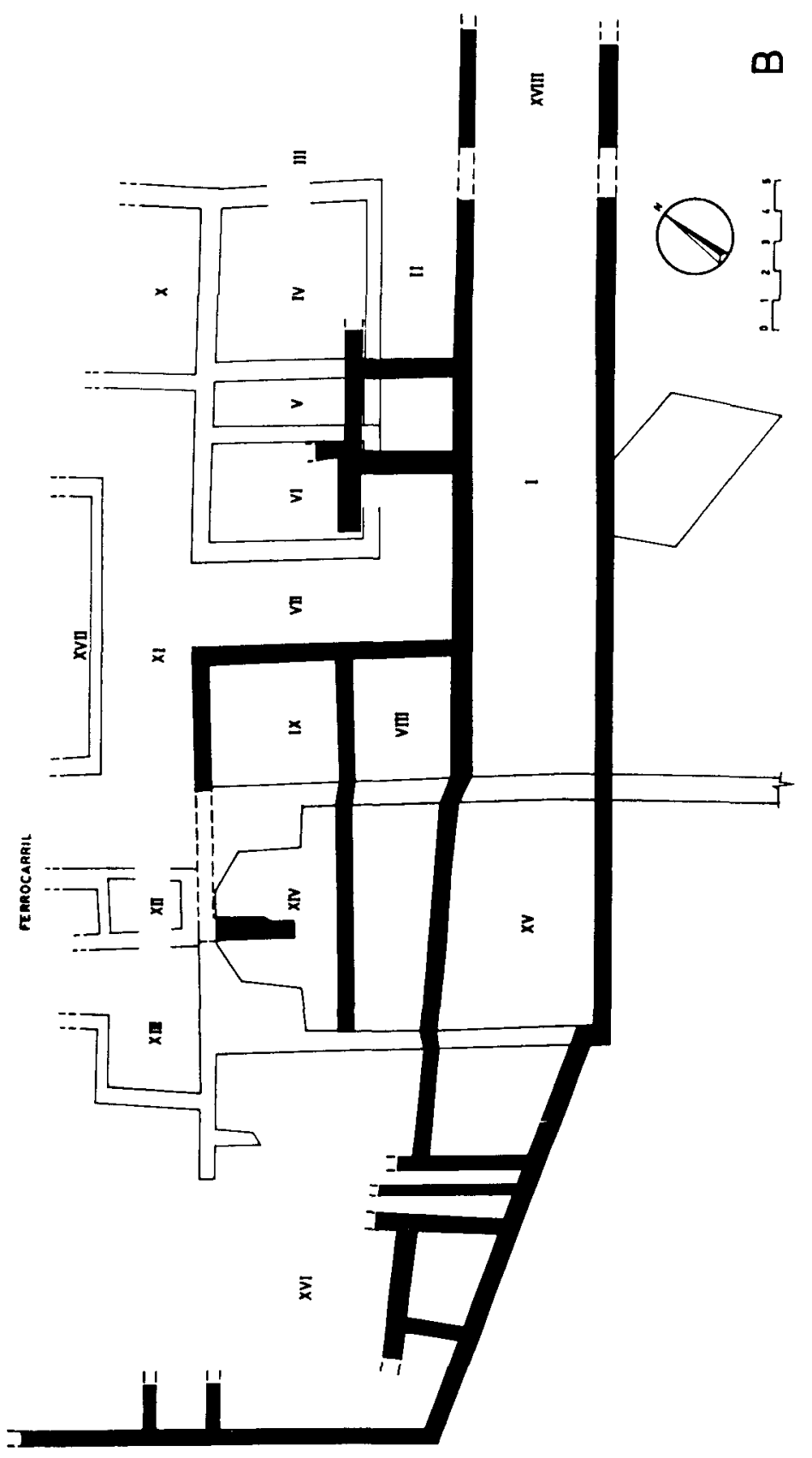

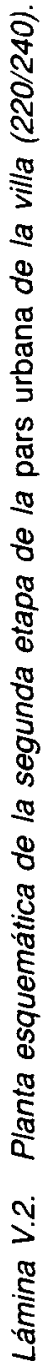


y las excavaciones han afectado un buen número. El cambio más evidente fue la supresión del póntico descrito en el párrafo anterior, que fue cerrado a Mediodía y se convirtió en un corredor (I), el cual integró los extremos de los cuerpos laterales que hasta entonces lo habian flanqueado. La puerta principal se situó en el extremo de Levante de la nueva fachada.

Al norte del sector I, donde antes parece que habia habido una zona libre, se levantó una retícula de habitaciones, construidas en dirección norte-sur, que eran de nueva planta o bien seguian el trazado del momento anterior (las ruinas de las nuevas se han podido observar en el subsuelo de los ámbitos II, IV-VI y VIII-IX). Por ahora hemos documentado dos alineaciones paralelas, la meridional adosada al muro norte del corredor y la septentrional a continuación del mismo. Estas habitaciones se veian interrumpidas por el pasillo VII, que a lo mejor se abrió entonces, aunque todavía no podemos demostrarlo, al no haber excavado.

También sabemos con certeza que el cierre occidental de las ruinas que han llegado hasta nosotros es de entonces, asi como dos paredes perpendiculares y solidarias (oeste de XVI). Por lo que atañe a las estructuras del ángulo suroeste de la vivienda, es muy dificil situarlas cronológicamente porque fueron privadas de su contexto en los años cincuenta, y las noticias que se dieron de la estratigrafía no son muy detalladas. A pesar de todo, opinamos que los muros de la etapa anterior continuaron en uso, excepto el cierre sur del ámbito $X V$, que se rectificó. En cuanto al tramo de la fachada que da el aspecto trapezoidal característico de esta parte del edificio se podría situar en la fase $\mathrm{B}$, y así lo hemos hechos provisionalmente, pero la forma de relacionarse con el cierre de Mediodía del cuerpo central es más bien confusa. Además, el muro de Poniente del oecus, que también pasa por este punto, acaba de complicar las cosas. Otra posibilidad sería que la casa hubiera mantenido un trazado rectangular, parecido al de la etapa $A$, pero hasta el momento no se han encontrado las ruinas que lo prueben.

Una vez aceptada la hipótesis de que el cierre trapezoidal es de la época $B$ se le deben asociar las dos paredes perpendiculares levantadas al sur de XVI, entre las que pasaba un desagüe.

\subsection{La reorganización del 350 (lám. VI.1)}

Antes de entrar en materia debe advertirse que el epigrafe de este apartado no debe condicionar al lector, puesto que nos referimos a una 


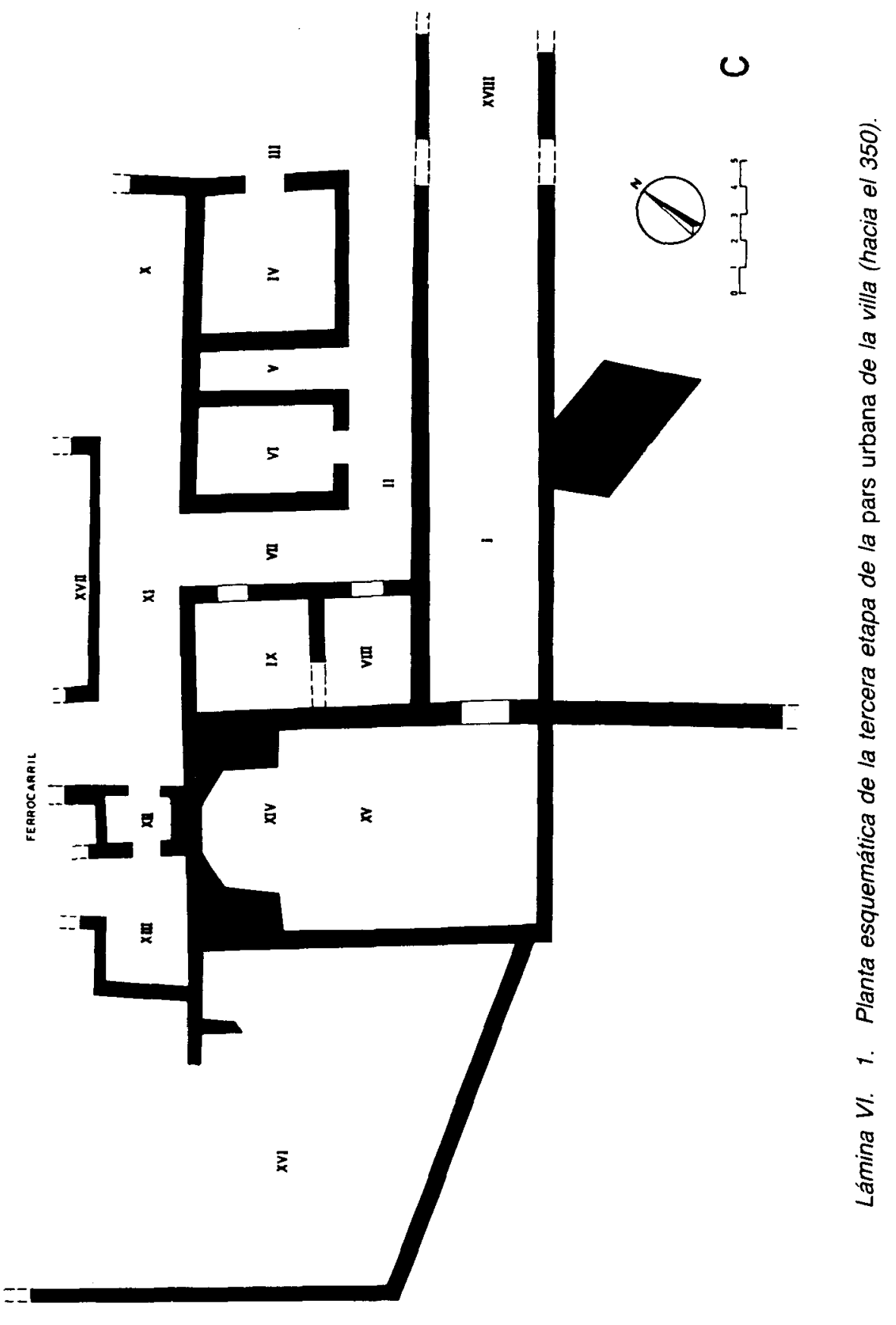




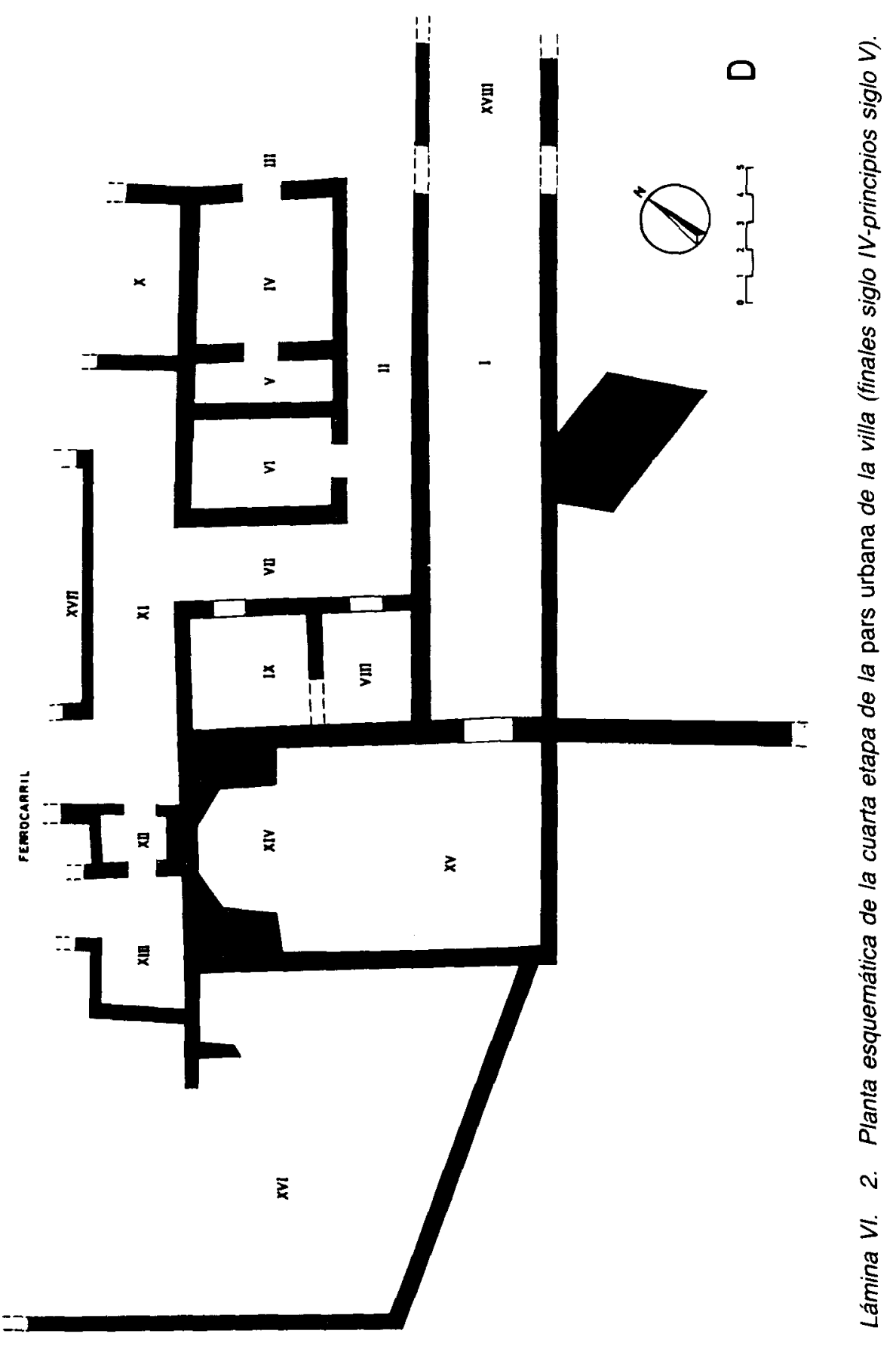


reorganización puramente arquitectónica. Queremos decir con ello que, como se desprende de las estratigrafias explicadas más arriba, la villa de Darró no padeció destrucción alguna a consecuencia de la crisis del siglo III. El profesor Arribas creía firmemente lo contrario y nosotros hemos meditado tal posibilidad. Sin embargo, el estudio exhaustivo de la sigillata africana - mucho mejor conocida ahora que hace treinta y cinco años - ha evidenciado que la única fase de derrumbamiento que hay en la villa de Darró es muy posterior a la invasión franca (infra: 2.5 ).

Todo esto no excluye la posibilidad de que la segunda mitad del siglo III fuese un período de crisis económica, pues en el yacimiento no se registró ningún tipo de actividad edilicia. De esta manera, los datos arqueológicos se podrian relacionar con una etapa de inestabilidad politica reconocida, pero no con los efectos de una razzia que cada vez parecen más débiles en toda España.

La compartimentación que refleja la mayor parte de los muros más elevados de las ruinas de la pars urbana data del ca. 350, el año en que empezó la etapa C. Su observación detenida demuestra la presencia de un cuerpo rectangular en el centro y otro trapezoidal al oeste. El núcleo principal de la construcción tenía un pasillo amplio o corredor a Medidodía (I), en cuyo extremo de Levante se encontraba la puerta principal. Casi enfrente de este acceso había otro para entrar en un pasillo, más estrecho y corto (II), limitado al norte por una serie de habitaciones rectangulares (IV-VI), las dos últimas abiertas a Mediodía y la primera a oriente. El pasillo II enlazaba con otro, trazado de norte a sur (VII), flanqueado por las habitaciones VIII y IX, que se le abrian, y la VI.

Al final de este espacio estaba el ámbito $\mathrm{XI}$, un vestíbulo que conducia a las estancias XII y XIII, o bien a los pasos que había a los lados del muro meridional de XVII. De estos pasajes, el oriental era mucho más amplio $y$ de hecho daba lugar al ámbito $X$. Todavia dentro del cuerpo principal, volviendo al corredor, se puede ver que desde su extremo de Poniente se accedía a una sala noble, la mayor del conjunto. Comprendía un aula rectangular trazada en dirección norte-sur (XV) y encabezada por un ábside pentagonal (XIV), precedido de una plataforma y un escalón. Sin duda, se trataba de un oecus de los que son característicos del período bajoimperial.

No tenemos demasiadas noticias del cuerpo trapezoidal, al haber desaparecido la mayoría de sus estructuras superficiales, pero la compartimentación, si la tenía, debía ser a base de paredes muy débiles. Otra incógnita — debida afortunadamente al alcance limitado de nuestra excavación- es la presencia de un muro perpendicular a la fachada del 
edificio, que continúa el trazado de la medianera entre el oecus y las habitaciones VIII-XI. De momento ignoramos su función, pues sólo se han excavado los estratos más superficiales que se le relacionan. En cuanto a su cronología, la hemos situado en esta fase porque este paramento se entrega claramente a la pared que cierra el cuerpo principal a Mediodia -que, como se recordará, es de la etapa B-.

Todos estos cambios dieron a las habitaciones IV, $V$ y $V I$ el aspecto que tiene ahora. La VIII y la IX fueron reformadas de nuevo, siempre siguiendo su trazado original, y se pavimentaron con opus signinum. El oecus, construido de nueva planta, anuló todas las habitaciones anteriores. Por otra parte, suponemos que los ámbitos XI, XII y XIII también se hicieron ex novo o al menos sufrieron reformas decisivas. Los dos últimos recintos daban por el lado de Poniente al cuerpo trapezoidal $(X V I)$, donde ya hemos dicho que han desaparecido todos los vestigios de esta época, salvo algunas manchas del pavimento de cal. Por Levante comunicaban con el final del pasillo VII y con el vestíbulo (XI). Debe recordarse que en este lugar se realizó el hallazgo de los fragmentos de opus signinum caídos en el suelo (supra: II.1). La situación de estos vestigios indica que la residencia del momento $C$ tuvo un piso elevado (o una terraza) pavimentado con signinum, que, como mínimo, rodeaba todo el ámbito XVII $o$, tal vez, se extendia por el resto del cuerpo principal, ya que en el extremo oriental del pasillo I o corredor hemos descubierto unas estructuras muy degradadas, que se podrían interpretar como los restos de una escalera. Si nuestras hipótesis son ciertas, es posible que esta planta alta se levantase en el periodo que describimos, teniendo en cuenta que se apoyaba en las estructuras del momento $\mathrm{C}$.

En cuanto a la presencia del peristilo hemos apuntado que podría haber sido el ámbito XVII. Esto sólo es una suposición, basada en la posición central que ocupa con respecto al resto de las ruinas conocidas. Por otra parte, será realmente difícil comprobar si tal propuesta es plausible porque el sector XVII se adentra bajo la via del tren, donde de momento no se puede excavar.

\subsection{Las modificaciones de finales del siglo IV o principios del $\mathrm{V}$ (lám. VI.2)}

Es el último momento en que hemos documentado transformaciones de las estructuras arquitectónicas de la villa. No fueron demasiado impor- 
tantes, pero revelan la vitalidad del establecimiento en una época que se acostumbra a considerar decadente o, como mínimo, oscura.

Entre los cambios realizados debe destacarse la nueva pavimentación con opus signinum de las habitaciones IV y V. Este suelo común también significó la unificación de ambas estancias, pues entonces se cerró el acceso de la habitación $V$ al pasillo II, y se abrió una puerta en la pared medianera de los dos ámbitos que describimos. Quizá esta ampliación se justifica en una nueva utilidad del espacio o la afirmación de la antigua. De momento es difícil señalar la función que pudo haber tenido el conjunto IV-V, pues no conocemos la planta completa de la casa. No obstante, teniendo en cuenta su anchura y orientación, se podria pensar en un triclinio, tal vez el de invierno.

Otra modificación de esta época es la configuración del ámbito $X$ como tal; en el momento anterior sólo era una esquina del vestíbulo XI, pero a principios del siglo $v$ se erigió una pared que cerró un recinto independiente. De todos modos debe advertirse que el paso al lado de XVII continuó abierto, aunque fuese más estrecho.

\section{Algunos paralelos}

La pars urbana de la villa de Darró, aunque conocida sólo a medias, empieza a tener la suficiente entidad como para plantearse sus paralelismos y tratar de asociarla con los diversos tipos de estructuras de esta indole. Del momento más antiguo excavado hasta ahora, correpondiente al siglo II (lám. V.1), se puede decir poco, ya que los hallazgos son fragmentarios. Con todo, la forma característica de la fachada, flanqueada por sendos cuerpos sobresalientes, se podría asociar a las villas llamadas "de torres en la fachada", de las cuales es un buen exponente el edificio de Murias de Beloño (Cenero, Asturias) ${ }^{22}$. Esta casa se ha datado en los siglos II-III, lo que corresponde bastante con la cronología establecida en Darró. De todas maneras, hasta que la excavación de las estructuras de la etapa A no haya avanzado algo más, es arriesgado proponer comparaciones con otros yacimientos concretos y... completos.

La vivienda rural romana del segundo cuarto de siglo III (lám. V.2) se conserva mucha más entera. Ello hace que nos recuerde la villa del Puig de Cebolla (Valencia), que tiene un cuerpo principal en forma de rectán-

22 Fernandez Castro, 1982: 163, figs. 38, 92 A, plano 37. 
gulo, dotado de corredor, y también presenta otro trapezoidal en uno de sus lados. Esta explotación, conocida hace tiempo, se ha fechado en los siglos II-III, mediante las esculturas que se encontraron durante su excavación ${ }^{23}$. También de planta rectangular con corredor, la villa de Daragoleja (Granada) se parece algo menos a la de Darró, pero podría corresponder al mismo tipo genérico. Sin embargo, su datación es mucho más tardia: segunda mitad del siglo $\mathrm{IV}^{24}$. La villa del Castillet (Cartagena, Murcia), en cambio, es muy similar a la nuestra: tiene planta rectangular, corredor y las ruinas encontradas son elocuentes. No obstante, su cronología de los siglos I al IV es muy imprecisa ${ }^{25}$.

Todas estas comparaciones también son válidas para el momento $\mathrm{C}$ de la pars urbana de Darró (lám. VI.1), fechado hacia el 350. Sim embargo, debe tenerse en cuenta la aparición de un elemento muy significativo: el oecus. Se trata de una estructura fácilmente identificable y, hasta cierto punto, corriente. Se conocen construcciones parecidas en diversos lugares: la villa de Sádaba (Zaragoza), donde el ábside es octogonal y fue erigido a mediados del siglo Iv; la villa de Almenara de Adaja (Valladolid), con un oecus de cabecera idéntica a la nuestra, que pertenece a la fase datada entre mediados del siglo IV y principios del $\mathrm{V}$; y la villa de Aguilafuente (Segovia), que posee una sala muy similar, también con cabecera pentagonal, situada en un momento que comprende desde mediados del siglo iv a mediados del $v^{26}$. Creemos que las ruinas halladas en estos lugares sitúan perfectamente nuestro oecus, pues, además de confirmar su función, reafirman su cronología.

\section{LA PARS RUSTICA DE LA VILLA (lám. VII)}

La excavación de este sector, llevada a término básicamente en los años 1987 y 1988, se programó para solucionar desde el punto de vista arqueológico los problemas urbanísticos que planteaba el área periférica del yacimiento, y al tiempo para profundizar en el conocimiento de las estructuras antiguas y de su evolución. Por esta razón, la investigación

\footnotetext{
Ibidem, 123-124, 163-164, figs. 87 D, 92 C, plano 46.

Ibidem, 126-128, 158, figs. $87 \mathrm{G}$, E, plano 26.

Ibidem, 83, 155-158, figs. $82 \mathrm{E}, 91 \mathrm{E}$, plano 20.

26 Ibidem, Sádaba: 98-100, fig. 83 D, plano 59; Almenara de Adaja: 102-104, 186-188, 279, figs. 8, 84 A, 97 D, plano 7; Aguilafuente: 104-105, 186-188, 279, figs. 5, 84 C, 97 E.
} 


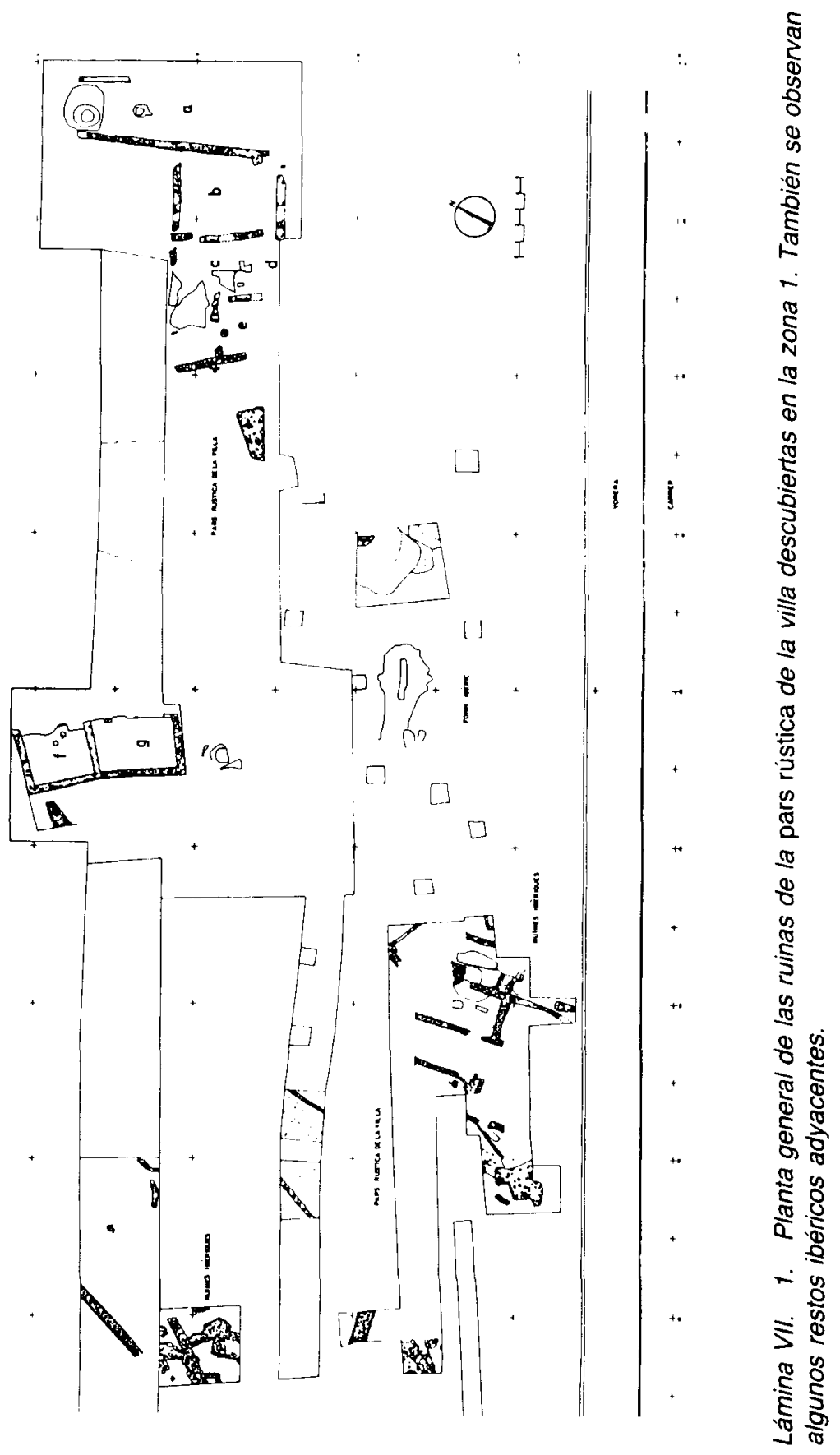


intensiva se inició en el extremo oriental del predio que llamamos «zona $1 »$. En este lugar se había detectado un sector estéril durante las prospecciones preliminares, pero también se habian observado algunos restos antiguos dispersos. Por consiguiente, era necesario delimitar la situación exacta de las ruinas y realizar su estudio, lo cual aconsejó realizar un sondeo amplio.

El primer descubrimiento en esta zona fue la impronta de una viña datable en el siglo XVIII, de la cual quedaban numerosos agujeros cuadrangulares bien alineados, donde habian estado las cepas. Este hallazgo debe relacionarse con los numerosos testimonios de la producción vitivinícola moderna localizados en la excavación, que son la fuente directa para conocer una actividad importante, descrita abundantemente en la documentación de la época.

\section{La serie de recintos descubierta a Levante (lám. VII.2)}

Después de los vestigios superficiales descritos, se encontraron los restos del yacimiento propiamente dichos. Se trataba de un grupo de estructuras de planta cuadrangular, formadas por muros de mamposteria bastante tosca, de los que en muchos casos sólo se conservaban las banquetas de cimentación o sus improntas en el terreno virgen. Todo el conjunto estaba muy arrasado, y si no hubiera sido por el riguroso método de excavación, podria haber pasado desapercibido, pues las arcillas naturales se encontraban pocos centímetros por debajo de la cota de los

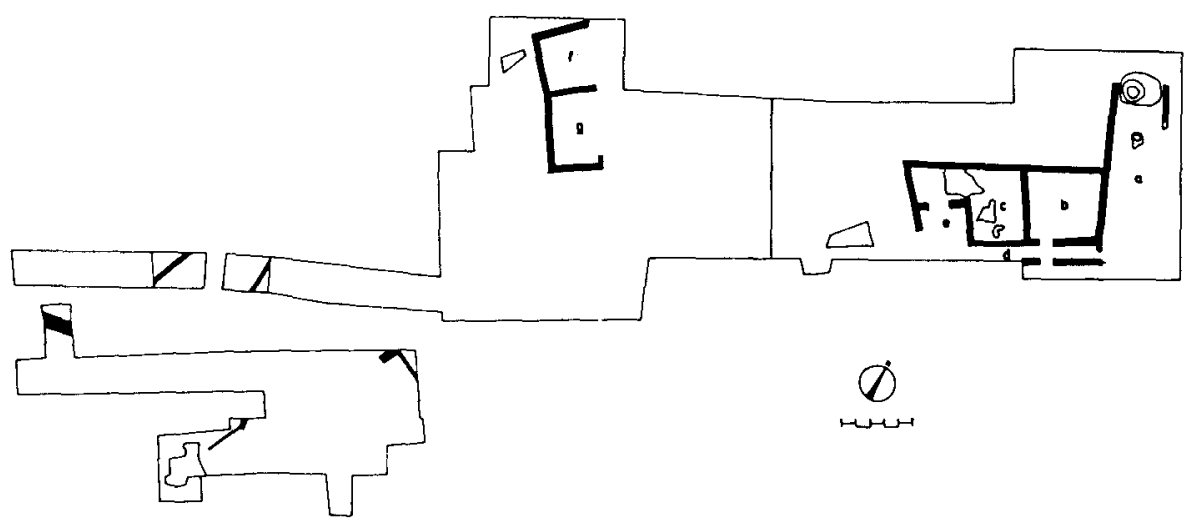

Lámina VII. 2. Planta esquemática de los mismos vestigios. 
campos de cultivo modernos. Este hecho habia ocasionado la desaparición de varios tramos de muro, y muchos recintos carecian de uno de sus límites. En cuanto a los pavimentos, sólo una estancia tenía restos de una especie de opus signinum y en otras quedaba parte de la preparación del suelo, a veces coronada por algún vestigio de éste. En general, los hallazgos no eran demasiado espectaculares, y costó un gran esfuerzo ponerlos de relieve, pero a través del estudio de la planta y gracias a la aparición del signinum mencionado hemos podido averiguar que estos restos pertenecian a una retícula aproximadamente rectangular. Seguramente alojaba diversas dependencias de la pars rustica de la villa, destinadas al proceso de transformación de las materias primas agricolas, tal vez para la obtención de aceite, vino o ambas cosas.

A estas alturas podemos diferenciar cinco estancias. La primera (a) se encuentra al nordeste del conjunto. Parece que tenia planta rectangular y sus dimensiones eran considerables. Ahora solamente quedan recortes en el terreno virgen, previos a la colocación de los muros oriental y meridional y la banqueta del occidental; la pared norte ha desaparecido completamente. Para construir este ámbito hubo que rebajar bastante el terreno natural, según indican los restos de un silo ibérico descubierto bajo el nivel teórico del pavimento: al construirse la estancia, este depósito de planta circular fue cortado por la mitad y rellenado. En medio del recinto se ha encontrado otro recorte en el terreno virgen; es relativamente pequeño, de planta subrectangular, y se practicó cuando el ámbito ya se utilizaba. Seguramente debe relacionarse con la presencia del contrapeso o el eje de un torcus. No se han encontrado vestigios del pavimento, lo cual es lógico, pues en este lugar el estrato superficial, de unos $15 \mathrm{~cm}$ de potencia, se apoyaba directamente en las arcillas estériles. Vale la pena advertir que se trata del punto donde el terreno natural alcanza una mayor altura.

La segunda estancia (b) está situada inmediatamente al oeste. Sólo se conservan las banquetas de los muros, a excepción del meridional, del que únicamente conocemos la impronta de argamasa depositada en el fondo de su trinchera de fundación, que da idea del trazado de la pared y de que, a lo mejor, tuvo una puerta; el pavimento era de tierra batida. Al lado de este recinto en dirección a Poniente, hay otro algo mayor (c). En este caso no se encontró señal alguna del cierre septentrional -aunque queda un pequeño fragmento de pared en el ángulo nordeste- y los restos del meridional eran muy confusos, por to que el trazado que presentamos en las ilustraciones es puramente teórico. En cambio, se documentaron las zapatas de los muros oriental y occidental, así como la puerta y las paredes que delimitaban una especie de vestí- 
bulo (e). El acceso se ha podido identificar porque en este lado la banqueta del muro no es continua y reproduce el desaparecido alzado de la pared; esta puerta tuvo un pilar central para reforzar el dintel. El pavimento de esta dependencia era una especie de sininum elemental. Constaba de una preparación de trozos de tejas y ánforas unidos con barro, sobre la que había una capa de unos $2 \mathrm{~cm}$ de cal.

Delante de los dos últimos recintos descritos $(b, c)$, quizá hubo un pasillo (d), delimitado por sus respectivas fachadas meridionales - por cierto, muy poco claras - y por la zapata de un muro desaparecido, en la que se observa una puerta, casi simétrica a la de b. Lógicamente esta nueva pared debe corresponder a otra dependencia, pero al no haberla excavado hasta ahora preferimos abstenernos de hipotetizar sobre ella.

En cuanto a la cronologia del conjunto, los restos de las preparaciones de algunos pavimentos han dado materiales de hacia finales del siglo IV o principios del v. Esto significa que las dependencias se han de asociar a la penúltima fase de funcionamiento de la pars urbana (I). Por lo que se refiere al abandono, las evidencias son precarias, como siempre, teniendo en cuenta la mínima potencia de los estratos, que además corresponden mayoritariamente a las paredes de tapial caídas. No obstante, algunas cerámicas son mucho más tardías que el resto del conjunto, y se podrian hacer llegar hasta el siglo vi. Se trata de una fecha relativamente avanzada, pero a nuestro entender la más adecuada, considerando otras evidencias procedentes de la propia pars rustica (infra).

\section{Las dos estancias al norte de la "zona 1" (lám. VII.2)}

Después de registrar los hallazgos descritos en el párrafo anterior, el área excavada se extendió hacia Poniente. Alli se completó una cata abierta en 1986, y se abrió una nueva trinchera estratigráfica. Gracias al primero de estos trabajos, se pudieron delimitar bastante bien dos estancias, aunque su lado de Levante se encontraba muy arrasado por los cultivos modernos. Sin duda, estos recintos habian pertenecido a la pars rustica: se trataba de ámbitos prácticamente cuadrados y ambos formaban un cuerpo rectangular ( $f$ al norte, $g$ al sur). Las paredes se construyeron mediante la técnica del enconfrado con una especie de opus caementicium. El pavimento era una capa fina y muy degradada de casi $1 \mathrm{~cm}$ de grosor. En el lado septentrional se apoyaban sobre el terreno virgen, $y$ en el meridional sobre un relleno depositado al levantarse el muro. Teniendo en cuenta el desnivel del terreno virgen en aquel lugar, 
la parte baja del paramento norte se adosaba a la arcilla natural recortada. Según parece, los accesos de ambas estancias eran independientes y se encontraban a Levante.

Debe destacarse que en la parte superior de la estratigrafía y cortados en los estratos de amortización, se encontraron los vestigios de dos tumbas de inhumación, muy deterioradas por los cultivos modernos. Los restos de esqueletos que contenian estaban orientados de este a oeste con la cabeza a Levante. Aparte de esto, no presentaban una tipología definida, pues las fosas eran muy simples, y la cubierta, si es que la hubo alguna vez, había desaparecido.

La excavación proporcionó una interesante serie de datos cronológicos: las estancias se construyeron hacia mediados del siglo III (lo cual coincide bastante bien con la fecha de la fase B de la pars urbana), tuvieron un período de uso relativamente largo y, al ser abandonadas, el lugar se utilizó para colocar los enterramientos, como pasó en la «zona 0" (lám. II.1), donde también hubo dependencias rústicas, por ahora poco conocidas. Los estratos en que estaban cortadas las tumbas han dado diversos materiales cerámicos y numismáticos de finales del siglo Iv o principios del $v$, pero también una pieza que puede llegar a la segunda mitad del siglo VI. La presencia de las inhumaciones, que lógicamente removieron la estratigrafia, hace que dudemos si los materiales mayoritarios (asociables a la data de las estancias a-e y la etapa $D$ de la pars urbana) corresponden al tapial de las paredes de estos recintos, que habrían podido ser reformados en un momento posterior a su fundación, o simplemente a su abandono. De todos modos, la pieza que puede fecharse en el siglo vi confirma nuestras expectativas sobre el prolongado período de funcionamiento de la villa.

\section{Las dependencias a Mediodia del centro de la "zona 1" (lám. VII.1)}

Casi al final de la campaña de 1987-1988 aparecieron otros restos de la pars rustica. De momento los conocemos escasamente, pues se encontraron en el curso de sondeos muy parciales, y tampoco podemos proponer hipótesis sobre su planta o su función. Los sondeos realizados sólo sirvieron para preparar las campañas siguientes, y consistieron en varias catas para delimitar en extensión esta área de las ruinas. No obstante, se comprobó que la potencia de los estratos del momento imperial era muy reducida —debajo aparecen estructuras ibéricas-. También se descubrió una dependencia tardía bastante grande, de planta rectangular 
y pavimentada con un trozeado de cerámicas parecido al opus signinum, que recuerda la técnica utilizada en el recinto $c$.

En cuanto a la cronología sólo sabemos que en uno de los ámbitos tanto las fundaciones como los estratos superiores daban materiales de la primera mitad del siglo il. Suponemos que los niveles superiores deben corresponder al derrumbamiento de las paredes de tapial. Asi, podemos asociar esta instalación concreta con la fase B de la pars urbana, pero para poder datar el conjunto habremos de esperar a su excavación completa.

4. La trinchera perpendicular al muro de cierre de la "pars urbana" (lám. II.2)

Después de completar estas investigaciones, que daban una idea bastante clara del tipo y la cronología de los vestigios de la mitad oriental de la "zona 1", emprendimos otros sondeos en el lado de Mediodía. En el centro del predio se trazó una trinchera perpendicular al muro meridional de cierre de la pars urbana.

En su extremo septentrional se documentó la existencia de un camino - ya citado al describir la $p$. u.-. Partía de la pared sur de la residencia y se dirigía en diagonal hacia el sudeste, probablemente al sector donde están las últimas dependencias de la pars rustica descubiertas parcialmente. Estaba empedrado con losas de piedra caliza que todavia conservaban algunas roderas. También tenia muestras de haber sufrido algunas reparaciones, realizadas con piedras más pequeñas, para regularizar las improntas dejadas por los carros.

Este camino debe relacionarse con el acceso más antiguo de la pars urbana de la villa. Por esta razón convendría datarlo, como mínimo, en el primer cuarto del siglo II, aunque no hemos excavado debajo suyo porque hemos preferido conservarlo in situ. El estrato de amortización no ha dado mucha información, como ya es habitual, pero las reparaciones -que si se han excavado- contenian cerámicas asociables a la última fase de la $p$. u. Ello significa que se utilizó hasta el abandono del edificio. Por otra parte, su trazado desde el noroeste hacia el sudeste, además de indicar que el camino iba hacia las dependencias rústicas, demuestra que bordeaba una zona de marismas que, como ahora veremos, no desapareció hasta el siglo "I avanzado. 
5. Las obras de drenaje. Algunas consideraciones sobre el medio físico

Dentro de la misma trinchera, algo más al sur, se realizó un sondeo que dio una estratigrafia aplicable a todo el extemo sureste del solar (según se comprobó en una larga serie de trincheras posteriores). Por debajo de la capa superficial aparecía un estrato de aportación en cuya cúspide se hallaban las estructuras del siglo XVIII -en este caso un pozo- Después apareció un suelo de tierra batida, fechado a finales del siglo Iv o principios del $v$. A continuación se encontró un relleno de considerable potencia, que empezaba con un estrato de arcillas - cuya parte superior quizá había sido un suelo- y continuaba con un nivel de grandes piedras mezcladas con fragmentos de tejas y ánforas. Debajo apareció una serie de niveles alternos de gravas $y$ arenas, que se terminaban -0 , mejor dicho, dejaban de poder documentarse- al llegar a la capa de agua freática. En la base de esta estratigrafía aparecía cerámica de la segunda mitad del siglo ॥.

Esta sucesión nos ilustra sobre la topografía original de Darró y los esfuerzos que se hicieron desde antiguo para modificarla. Teniendo en cuenta éste y otros hallazgos ${ }^{27}$, suponemos que en el lugar existió la desembocadura de un curso fluvial, que seguramente formaba un delta, cuyos vestigios actuales son los torrentes de Sant Gervasi y Sant Joan. Uno de los brazos de la corriente debería pasar por la base de la colina de Sant Gervasi y se extendería hacia Levante hasta el centro de la "zona 1"; quizá su límite oriental se encontraba algo más alejado de las actuales ruinas de la pars urbana de la villa.

Las excavaciones han demostrado que desde bien pronto (mediados del siglo IV a.C.). empezaron los trabajos para ganar terreno al delta. Prosiguieron a lo largo de la etapa ibérica más tardía y seguramente se prolongaron durante el siglo I, aunque de momento no tenemos demasiadas noticias sobre estos últimos. Sin embargo, sabemos que hacia la época de Trajano, al construirse el sector de la pars urbana que conocemos, el brazo occidental del delta ya estaba bastante colmatado. Ello posibilitó la erección del dificio. Sin embargo, el proceso de desecación no se terminó definitivamente hasta la segunda mitad del siglo $\mathrm{H}$, y la estratigrafía mencionada más arriba es el testimonio de los últimos trabajos realizados.

27 Lopez Mullor, Fierro, 1988 c. 


\section{EL ALFAR ROMANO}

Se encontró durante la campaña de 1985 y se excavó al año siguiente. Conocemos sus elementos esenciales que son dos hornos gemelos, una dependencia anexa y una balsa para decantar las arcillas usadas como materia prima.

\section{Los hornos (láms. VIII.1, VIII.2: H1, H2)}

Tienen idéntica estructura y distribución interna, si bien el que hemos designado con el número 2 fue objeto de reformas que modificaron su funcionamiento. En ambos casos, la parte conservada corresponde a la cámara de combustión, parcialmente cortada en el terreno natural, y al praefurnium que se abre a la dependencia anexa. Están orientados de norte a sur, con el portillo de alimentación de la cámara de fuego a Mediodía. La separación entre ellos es de $1,95 \mathrm{~m}$. Las dos instalaciones son de planta rectangular y están construidas con adobe de $30 \times 15 \times$ $7 \mathrm{~cm}$ aproximadamente. Este material forma los muros perimetrales, así como los elementos de sustentación de la parrilla.

Para la construcción de los hornos se realizaron dos operaciones. Primero se recortó el terreno natural arcilloso (con el cual se debieron elaborar los adobes) y después se construyeron las paredes perimetrales mediante la colocación de los ladrillos crudos que, salvo en la cara meridional, se adosaron a las arcillas virgenes. En el lado de Mediodía se levantó un muro de mampostería en el que se dejó un espacio para colocar el praefurnium. A este muro se le adosaron internamente los ladrillos que configuraban el horno propiamente dicho.

En el interior de las cámaras de fuego de ambos hornos apareció una serie de estructuras construidas con ladrillos y revestimientos arcillosos refractarios. Se trataba de unos estribos laterales adosados a los muros más largos de la instalación. Estos elementos de sustentación se completaban con otro central en forma de espina, adosados a la pared del fondo, del que arrancaban nuevos estribos orientados hacia derecha e izquierda. Delante de la boca del praefurnium sólo existian estribos en los muros laterales, pues la espina terminaba un trecho antes de llegar al conducto de alimentación. En este sector se hallaron los arranques de un solo arco cuya luz seria igual a la anchura inierior de la cámara, disponiendo además de unos estribos más gruesos.

Así, en cada uno de los dos hornos, empezando a contar desde la 
boca, existian los arranques de un primer arco único y, a continuación, los restos de cinco arcadas paralelas. Esta disposición indica que los vestigios corresponden a la sustentación de dos hileras de arcos paralelos, sobre los que debía estar la parrilla, que no se ha conservado. El arco único del principio serviría para crear un espacio despejado, a modo de vestíbulo, que facilitaría la alimentación y la limpieza de las dos mitades simétricas en que estaba dividida la cámara de combustión. Además de sostener las arcadas, los elementos laterales ayudaban a alinear las chimeneas que calentaban el piso superior y permitían la aireación del proceso de combustión. También ejercian la función de contrafuertes, evitando los empujes laterales de las tierras a las que se hallaban materialmente pegadas las bases de los hornos.

Los praefurnia tenía $2,37 \mathrm{~m}$ de largo por $1 \mathrm{~m}$ de ancho. Su altura debía ser ligeramente inferior a la de las cámaras de combustión respectivas. Eran de adobe y su remate consistía en una bóveda de medio cañón (de la que se han encontrado los arranques en ambos casos). Exteriormente estaban protegidos por unos muretes que también servian de contrafuertes. Junto a las entradas de ambos se localizó un pequeño zócalo que debió servir para ajustar el cierre del conducto de alimentación en las últimas cocciones.

El hecho de haberse documentado las escombreras al norte de la zona excavada hace pensar que el lugar por donde se alimentaban las cámaras de cocción estaba en el lado opuesto al de los praefurnia. A Mediodía estaba la que hemos llamado dependencia anexa, que servía para almacenar el combustible y recoger las cenizas.

Los vestigios encontrados sugieren que la apariencia general de ambos ingenios era semejante, aunque el horno 2 experimentó algunos cambios a causa de unas reformas posteriores a su fundación ${ }^{28}$ : el praefurnium abovedado daba paso a una cámara de fuego rectangular. En este lugar estaban los arcos de sustentación de la parrilla. Este último elemento no se ha encontrado in situ, pero, a juzgar por los materiales localizados en el estrato de derrumbamiento, debió ser de ladrillos rectangulares de $30 \times 20 \mathrm{~cm}$. Estos elementos en ciertos casos, presentaban una alineación de orificios muy toscos, que servirian para comunicar el

${ }^{28}$ Las modificaciones consistieron en la apertura de una gran chimenea de planta circular, inmediatamente al norte de la cámara de fuego, y en la reparación de los estribos -y por consiguiente los arcos - que sustentaban la parrila, la cual seguramente también sufrio algún cambio. Por último, en el siglo xvill se construyó un pozo al este del ingenio que afectó bastante la pared de ese lado, desfigurando la planta general. 
calor desde la cámara de fuego. El laboratorio de cocción tampoco se ha conservado, pero debemos suponer que era hemisférico o abovedado. Los muy abundantes restos de ladrillos encontrados sugieren que también fue edificado con estos materiales.

\section{La dependencia anexa (láms. VIII.1, VIII.2: DA)}

Al sur de los hornos se encontró un recinto rectangular construido con mamposteria unida con barro. Sus lados menores se hallaban orientados de norte a sur; al norte se encontraban los praefurnia descritos antes, y al sur, una puerta. Esta dependencia servia para proteger los mencionados conductos de alimentación de los hornos, almacenar la leña y depositar las cenizas, después de limpiar el interior de las cámaras de fuego. El pavimento original de la dependencia era el propio terreno virgen, recortado para ponerlo al mismo nivel que el interior de los hornos. Los muros, por el contrario, se hallaban sobre las arcillas naturales, en una cota más alta silueteando la zona recortada. Por esta razón fue necesario colocar un escalón interior en la puerta. La cubierta suponemos que era de tegulae e imbrices sostenida por puntales de madera, que se apoyaban sobre las paredes perimetrales, un pilar central y una pilastra adosada al muro de Mediodía.

\section{La balsa de decantación (láms. VIII.1, VIII.2: BD)}

Al noroeste de los hornos se descubrió un recinto prácticamente cuadrado. Sus paredes eran bastante toscas, construidas con ripios y mortero de cal, y su cara externa no era vista por hallarse adosada al terreno. Ya en el interior, en el ángulo noroeste, presentaba una agrupación de tegulae colocadas planas, que daban la impresión de ser escalones. El pavimento era de tierra batida, y los muros se hallaban enlucidos con cal y presentaban una rebaba a la altura del suelo. El relleno descubierto indica que se trataba del lugar para depurar las arcillas que aparecen en esta zona del subsuelo del yacimiento.

\section{La producción (lám. IX)}

La figlina de Darró manufacturó ánforas de las formas Pascual 1, Dr. 7-11 y Dr. 2-4. Del primero y el segundo tipo tenemos fragmentos lo suficientemente elocuentes como para determinar su tipología sin ninguna 


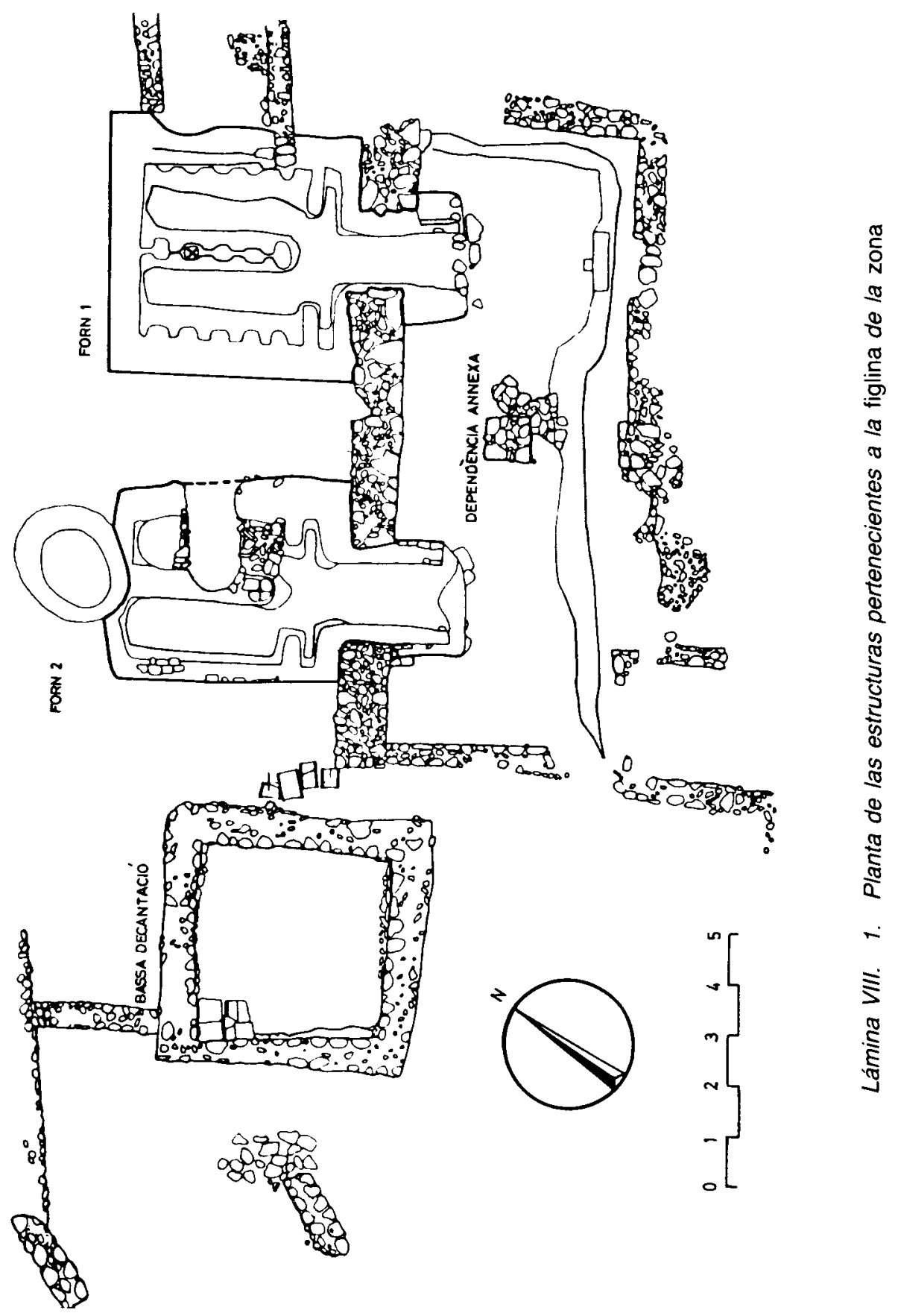




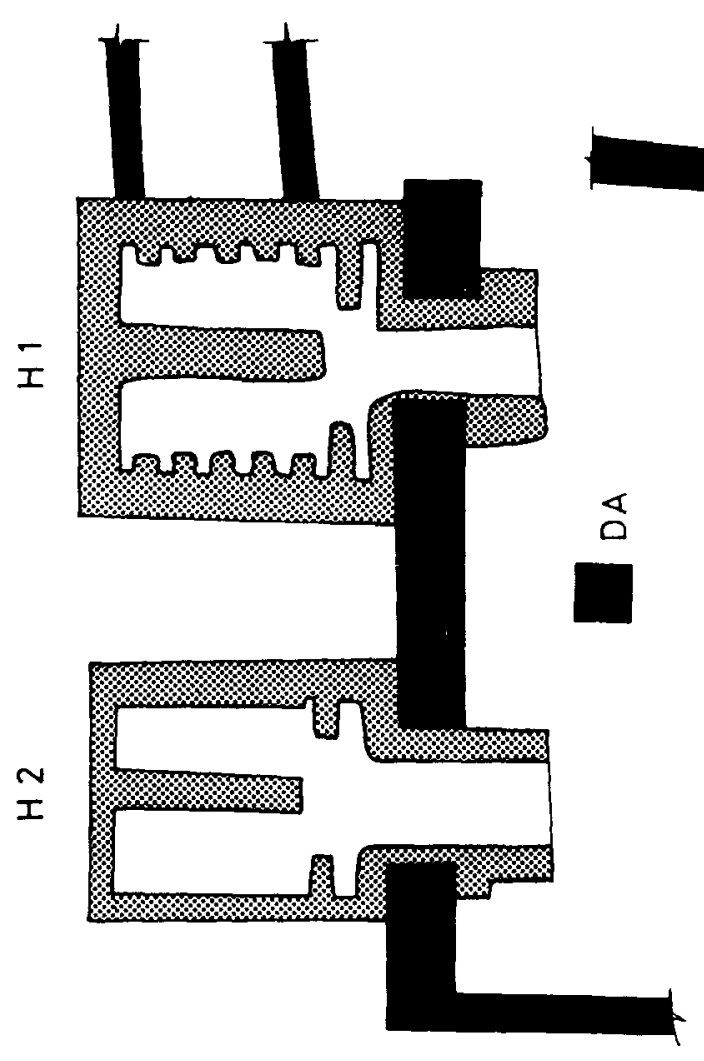

D்

$\rightarrow$

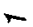
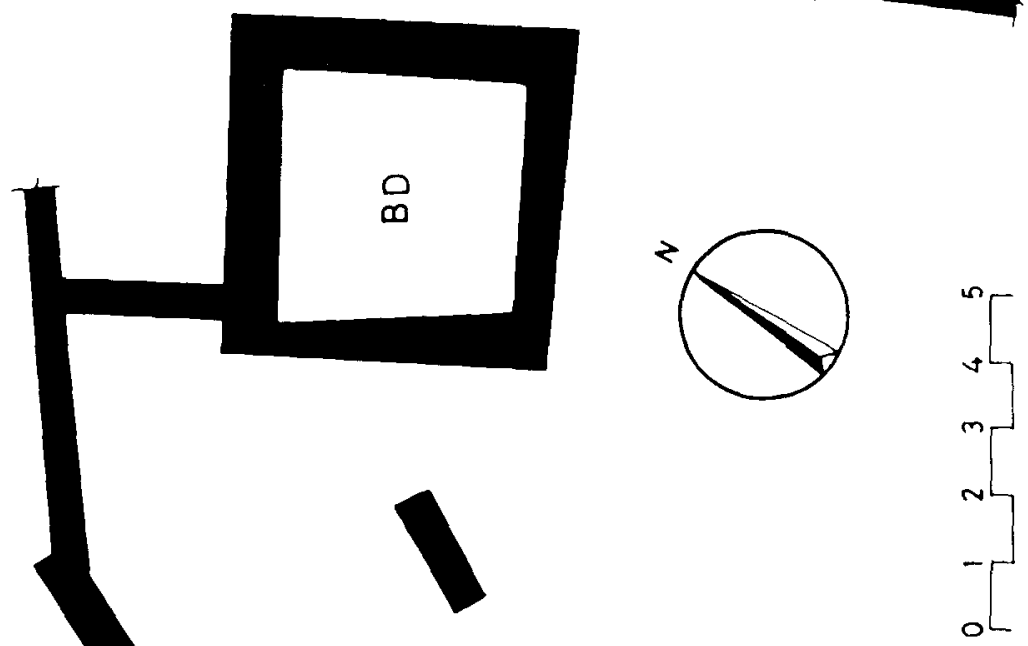
duda. En cambio, del tercero por ahora sólo poseemos labios y algún asa acodada. A pesar de que seguramente estos fragmentos habrán de asociarse a la forma enunciada, no constituyen ejemplares demasiado típicos.

La presencia de ánforas Pascual 1 en los yacimientos del litoral catalán se conoce muy bien ${ }^{29}$. No pasa lo mismo con el tipo 7-11, aunque existen diversos ejemplos de su producción en la costa oriental de la Tarraconense ${ }^{30}$. La forma Dr. 2-4 es abundante en Cataluña ${ }^{31}$. Todos los envases de Darró presentan rasgos muy peculiares. En primer lugar, la pasta: se parece mucho a la que aparece en las manufacturas más antiguas propias del yacimiento: cerámicas ibéricas y una hipotética imitación de ánforas punico-ebusitanas ${ }^{32}$. Según los casos, aunque sin vinculación directa con tal o cual forma, la pasta puede ser rosada, amarilla, verdosa o bicolor, combinándose los tonos anteriores. El desgrasante es muy fino, de partículas blancas, rojizas y mica dorada, que se aprecian difícilmente a simple vista. Estos caracteres tecnológicos se alejan de los que identifican, por ejemplo, a la mayor parte de las ánforas de la región layetana, la más conocidas ${ }^{33}$.

La otra particularidad de los envases de Darró es su morfología. Las ánforas Pascual 1 son formalmente típicas, aunque sus labios resultan bastante heterogéneos (lám. IX.1-7). Los bordes del tipo Dr. 2-4 (lám. IX.8-14) son todavía más poco comunes y recuerdan a las formas $\mathrm{Dr}$. 28-30. De todos modos, al no haber encontrado hasta ahora ningún fragmento de fondo o asa de esta última clase de ánforas - muy características, por cierto- podemos descartar esta filiación ${ }^{34}$. En cuanto al tipo

29 Este tipo de dio a conocer en: Pascual, 1962; sintesis sobre la producción en el Maresme: Miró, 1982-1983: 229-231; un buen repertorio de trabajos sobre el tema en el simposio "El vi a l'antiguitat".

30 Tivissa (TChernia, 1971, fig. 18; Nolla, Padro, Sanmarti, 1979; Idem, 1980), Cervera del Maestrat (BorRAs, 1988), Jávea (ARANEGul, 1981: 533-534). En Can Tintorer, El Papiol, pudo haber habido otra producción: JuLIA et alii, 1989: 289-294. En las excavaciones que uno de nosotros lleva a cabo en el centro productor de Sant Boi de Llobregat también han aparecido algunos fragmentos de Dr. 7-11, pero ahora es demasiado pronto para asociarlos a las formas locales, PASCUAL 1 y Dr. 2-4.

31 Difusión: Pascual, 1977; CORSi-ScIallano, LIOU, 1985: 148-152; LIOU, 1987, y diversas referencias en el simposio "El vi a l'antiguitat".

32 LOPEZ MULLOR, 1989 b.

33 No obstante, hubo centros de producción que utilizaron pastas amarillas: $v$. gr. Sant Boi de Llobregat (PAscual., 1977: 50); Can Pedrerol de Baix, Castellbisbal (/bidem: 51); Can Tintorer, El Papiol (lbidem: 53, JuliA et alii, 1989: 291); Badalona (Ibidem: 59); Can Collet, Llinars del Valles (lbidem: 67); Barcelona (Granados, Rovira, 1987: 128 s.). También, fuera de éste área, en: Reus (TCHERnIA, 1971: 59) y Llafranc (Nolla, CANES, RoCAS, 1982: 170).

${ }^{34}$ Estos productos suelen ser gálicos y su estudio se halla muy avanzado (Montans: LEQUeMENT, 1983: 499-501; Aspiran: TCHERNiA, 1971; GeNTY, FICHES, 1978; sintesis en: LAU. 


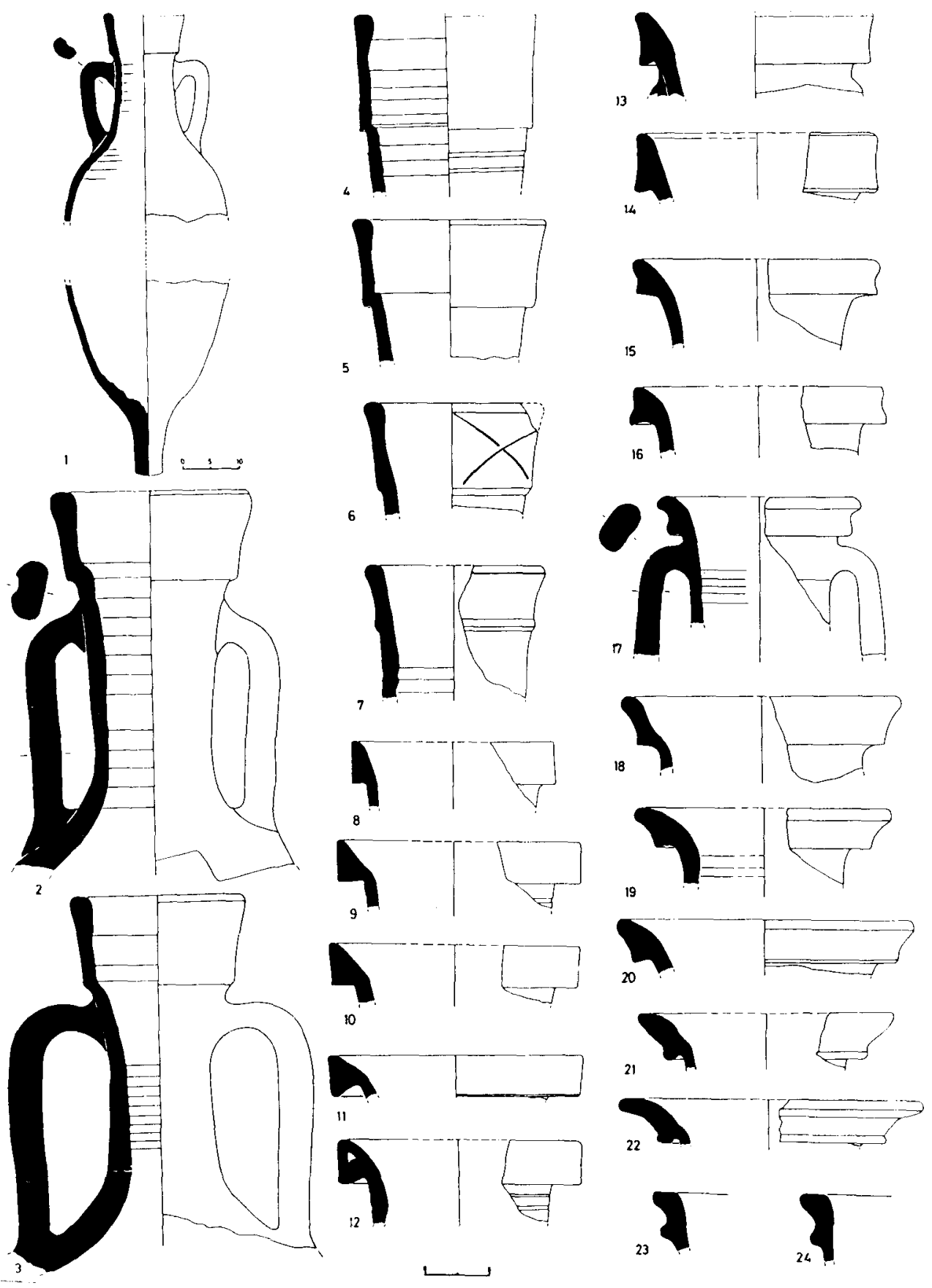

Lámina IX. Algunos exponentes de los tipos de ánfora producidos en el alfar del siglo I: 1-7, Dr.-Pascual 1; 8-14, Dr. 2-4 (?); 15-24, Dr. 7-11. 
7-11 (lám. IX.15-24), su abundancia es elocuente y su identificación no plantea ningún problema. Por fin, se ha de mencionar el hallazgo hace unos años de un ánfora de fondo plano en una escombrera. Entonces pensamos que también era una producción local, pero ahora tenemos dudas al no haber localizado ninguna más durante la excavación de los hornos. Por otra parte, el único paralelo que conocemos procede de un pecio bastante tardio ${ }^{35}$.

Por lo que se refiere a la cronología de las ánforas y el taller mismo, la sucesión estratigráfica no ayuda demasiado, ya que no se ha encontrado ningún fragmento de cerámica fina en los estratos de abandono ni en los de la primera etapa de uso. La fundación es imposible de comprobar porque, como se recordará, todas las estructuras están recortadas en el terreno virgen sin ninguna trinchera. A pesar de todo, la datación de los diversos tipos de ánforas hace pensar que la figlina habría podido empezar a funcionar hacia el 30 a.C y prolongar su actividad hasta finales del siglo। aproximadamente.

En el sector de la balsa de decantación han aparecido algunas cerámicas de la segunda mitad del siglo III, pero esto indica una reutilización concreta de aquel lugar, ya que en el subsuelo del aula del oecus apareció un estrato con muchos fragmentos de ánfora y paredes de horno, ya amortizados en la época de Trajano (supra: II.4).

BENHEIMER, 1985), pero también se manufacturaron en ciertos talleres hispánicos: p. e., Santa Maria de les Feixes, Cerdanyola (PAScuAL, 1977: 68-69); Llafranc (supra); Mas d'Aragó, Cervera del Maestrat (supra); L'Almadrava, Dènia (GisBERT, 1987: 112, fig. 2). Por otra parte, los labios que presentamos también se parecen a los del tipo PE 25 (RAMÓN, 1981: 113-116, sistematizado por este autor, pero identificado antes por Cerdà, quien le llamó “Dressel 1 provincial»), cuya cronologia es similar. Acaso el parecido se deba a que ambas clases de ánforas parten del mismo modelo: la Dr. 2-4 "clásica".

35 Publicación del hallazgo: Lopez Mullor, Ferrer Marti, 1982 d; Miro $(1988,27.1)$ se hizo eco del mismo, dando la forma como local; lo mismo recoge BeLtRÁn LLORIS, citando el tipo de Miró (1990, fig. 115, n. ${ }^{\circ}$ 995). No obstante, de momento no podemos seguir sosteniendo ese origen, que nosotros mismos propusimos al dar a conocer la pieza. En primer lugar, ya se ha dicho, por no haber encontrado ningún otro fragmento y, en segundo lugar, por el parecido de esta ánfora con las publicadas - poco después de aparecer nuestro artículo_ procedentes del pecio Sud-Lavezzi 1 (LıOU, 1982: 440-444, figs. 1.5, 2.5), fechadas en el siglo IV o principios del v. Esta misma cronología es la que proporcionó un segundo lote de material también reflejado en nuestro trabajo de referencia. Teniendo en cuenta que todas las piezas citadas procedian de un sondeo incontrolado, abierto para colocar una tubería de agua, y que llegaron a nuestras manos exentas del más mínimo contexto, el ánfora que nos ocupa bien pudiera pertenecer al lote bajoimperial. Por todo ello, de no realizarse nuevos hallazgos esclarecedores, pensamos que este envase pudiera ser un paralelo del material hallado en el pecio corso y, por lo tanto, datarse en los siglos IV$\checkmark$ y proceder de Lusitania, según propone Liou. 


\section{BIBLIOGRAFÍA}

Almagro, M.; Serra Rajfols, J. C.; Colominas, J., 1945: Carta Arqueológica de España. Barcelona, Madrid.

ARANEGUI, C., 1981: “La producción de ánforas en el País Valenciano: estado de la cuestión", Archivo de Prehistoria Levantina, XVI, 529538.

ARRIBAS, A., 1956: «La primera campaña de excavaciones en el poblado ibérico y la "villa" romana de Adarró", Boletín del Centro de Estudios de la Biblioteca-Museo Víctor Balaguer, IV, 23-48.

- 1959: “El poblado ibérico y la villa romana de Adarró (Villanueva y Geltrú", Ampurias, XX, 323-329.

Beltrán LloRis, M., 1990: Guía de la cerámica romana. Zaragoza.

BorrÁs, C., 1988: "Más d'Aragó. Cervera del Maestrat, Baix Maestrat», Memòries Arqueologiques de la Comunitat Valenciana, 1984-1985. Valencia, 147-151.

Castellano, A., 1986: "La inscripció votiva romana del turó de Sant Gervasi”, Memòria 1984, 148-150 (ed. conjunta en catalán, castellano e inglés).

ClUA, M., 1989: "Les monedes trobades a les excavacions de l'establiment ibèric i la vil.la romana de Darró (Vilanova i la Geltrú) durant els darrers anys", Miscel/lània Penedesenca, XIII.

COROLEU, J., 1979: Historia de Villanueva y Geltrú. Vilanova i la Geltrú (2. ${ }^{\mathrm{a}}$ ed.).

CORSI-SCIALlanO, M.; LIOU, B., 1985: "Les épaves de Tarraconaise à chargement d'amphores Dressel 2-4", Archaeonautica, 5. París.

Fernandez Castro, M. C., 1982: Villas romanas en España. Madrid.

FerRer SOler, A., 1944: "Restos de una villa romana en Villanueva y Geltrú», Ampurias, VI, 334-336. 
- 1947-1948: «El poblamiento ibérico del Panadés y extensiones», Ampurias, IX-X, 272-286.

- 1955: «Prospecciones en yacimientos romanos de Sitges y Villanueva y Geltrú», AEArq, XXVIII, 174-179.

Ferrer I Marti, A., 1978: «El poblat ibero-romà de Darró de nou al descobert», IA, 26, 24-28.

Granados, J. O.; Rovira, C., 1987: "Tres nous centres de producció d'àmfores a l'ager de la Colonia Barcino", El vi a l'antiguitat, 126132.

GENTY, P.-Y.; FICHES, J.-L., 1978: “L'atelier de potiers gallo-romains d'Aspiran (Hérault). Synthèse des travaux de 1971 à 1978", Figlina, 3, 71-92.

GISBERT, J. A., 1987: “La producció de vi al territori de Dianium durant I'Alt Imperi: el taller d'ámfores de la vil.la romana de l'Almadrava (Setla-Mirarosa-Miraflor)", El vi a l'antiguitat, 104-118.

GumA, M., 1990: La sigil.lata clara i la ceràmica fina baix-imperial a Darró (Vilanova i la Geltrú). Barcelona, Memoria de Licenciatura (inédita), Universidad de Barcelona, Facultad de Geografía e Historia.

JULIA, M. et, alii, 1989: "La vil.la romana de Can Tintorer (El Papiol)», Baix Llobregat, 286-302.

LAUBENHeIMER, F., 1985: La production des amphores en Gaule Narbonnaise. Paris.

Lequément, R., 1983: “Circonscription de Midi-Pyrenées, Montans», GaIlia, 41, 499-501.

Liou, B., 1982: "Direction des recherches archéologiques sous-marines. Corse du Sud", Gallia, 40, 437-454.

- 1987: "L'exportation du vin de Tarraconaise d'après les épaves", El vi a l'antiguitat, 271-284.

LOPEZ MULLOR, A., 1980: "Una peculiar producción de paredes finas en la costa catalana", Rivista di Studi Liguri, XLVI, 33-40.

- 1986: “Establiment ibèric i romà de Darró", Memòria 1984, 113-142. (ed. conjunta en catalán, castellano e inglés).

- 1989 a: Las cerámicas romanas de paredes finas en Cataluña, 2 vols., Diputació de Barcelona. Barcelona (2. ${ }^{a}$ ed. Zaragoza, 1990).

- 1989 b: "Nota preliminar sobre la producción anfórica de Darró, Vilanova i la Geltrú (Barcelona)", Société Française d'Etude de la Céramique Antique en Gaule. Actes du Congrés de Lezoux. Marsella: 109-122.

- En prensa: “Retrobament d'una inscripció romana a la vil-la del castell de Castelldefels», Baix Llobregat.

López Mullor, A.; Ferrer Marti, A., 1982 a: "Avenç dels resultats de les excavacions a l'establiment ibèric i romà de Darró (1977-1981)",, 
Butlleti del Centre d'Estudis de la Biblioteca-Museu Victor Balaguer, 177-198. Ídem en lengua castellana en Homenaje a M. Almagro Basch, III. Madrid, 1984, 109-119.

- 1982 b: "Darró o Adarró o Aderró. Vilanova i la Geltrú", Les excavacions arqueològiques a Catalunya en els darrers anys. Barcelona, 342-344.

- 1982 c: “Notes d'Arqueologia de Catalunya. Vilanova i la Geltrú», IA, $38,47-49$.

- $1982 \mathrm{~d}$ : «Hallazgos anfóricos en el establecimiento ibérico y romano de Darró (Vilanova i la Geltrú)", IA, 39, 82-89.

lopez Mullor, A.; Ferrer Marti, A.; Mormeneo, LI., 1981: “Materials superficials recollits al poblat ibero-romà de Darró (Vilanova i la Geltrú)», Butlleti del Centre d'Estudis de la Biblioteca-Museu Victor Balaguer, s/n., 123-140.

López Mullor, A.; Fierro Macía, X., 1987: "Les excavacions al conjunt de Darró durant l'any 1986», Primera Edició (Vilanova i la Geltrú), 1, 5-12.

- 1988 a: «La campanya d'excavacions de 1987 a l'assentament ibèric $i$ la vil.la romana de Darró», Primera Edició (Vilanova i la Geltrú), 2.

- 1988 b: “Darreres intervencions a l'assentament ibèric i la vil.la romana de Darró (Vilanova i la Geltrú, Garraf)", Tribuna d'Arqueologia, 1987-1988. Barcelona, 53-68.

- 1988 c: "La época ibérica en Darró, Vilanova i la Geltrú, Barcelona. Evidencias e hipótesis proporcionadas por las últimas excavaciones (1984-1988)", Espacio, Tiempo y Forma, 1, serie II, Historia Antigua, 117-142.

MiRó, J., 1982-1983: “La producció d'àmfores al Maresme: una síntesi», Laietània, 2-3, 238-244.

- 1988: "La producción de ánforas en Catalunya. Un estudio sobre el comercio del vino de la Tarraconense (siglos 1 a.C.-I d.C.)", BAR, 473. Oxford.

Nolla, J. M.; Canes, J. M.; Rocas X., 1982: “Un forn de terrissa a Llafranc (Palafrugell, Baix Empordà). Excavacions 1980-1981", Ampurias, 44, 147-183.

Nolla, J. M., Padró, J.; Sanmarti, E., 1979: «Algunes consideracions sobre el forn d'àmfores de Tivissa (Rivera d'Ebre)", IA, 30, 151-153.

- 1980: «Exploració preliminar del forn d'àmfores de Tivissa (Ribera d'Ebre)», Cypsela, III, 193-218.

PASCuAL, R., 1962: «Centros de producción y difusión geográfica de un tipo de ánfora", VII Congreso Nacional de Arqueología. Zaragoza, 334-335. 
- 1977: "Las ánforas de la Layetania», Méthodes classiques et métodes formelles dans l'étude des amphores. Roma, 67-68.

RAMÓN, J., 1981: La producción anfórica púnico-ebusitana. Ibiza.

TCHERNIA, A., 1971: "Les amphores vinaires de Tarraconaise et leur exportation au début de l'Empire", AEArq, 44, 38-85.

Tovar, A.; Blazquez, J. M., 1975: Historia de la Hispania Romana. La Península lbérica desde el 218 a.C. hasta el siglo V. Madrid.

VIRELLA, A., 1978: "De quan Vilanova i la Geltrú era un empori de la vinya i el vi», Miscel/lània Penedesenca, 205-240.

Abreviaturas

AEArq: Archivo Español de Arqueologia.

Baix Llobregat: I Jornades Arqueologiques del Baix Llobregat. Castelldefels, 1989 (preactas no completas).

El vi a l'antiguitat: El vi a l'antiguitat. Economia, producció $i$ comerç en el Mediterrani Occidental. Badalona, 1987.

IA: Informació Arqueológica. Barcelona.

Mèmoria 1984: Servei de Catalogació i Conservació de Monuments de la Diputació de Barcelona. Memòria 1984. Barcelona, 1986. 